\title{
Assessment of digital EEG, quantitative EEG, and EEG brain mapping: Report of the American Academy of Neurology and the
American Clinical Neurophysiology Society*
}

Marc Nuwer, MD, $\mathrm{PhD}$

Digital EEG techniques have grown rapidly in popularity for recording, reviewing, and storing EEG. Digital EEG recordings are flexible in the way they display the EEG tracings, unlike analog paper EEG. Montage, filter, and gain settings can be changed retrospectively during record review. Quantitative EEG (QEEG) analysis techniques can provide additional measurements or displays of EEG in ways not available with analog paper EEG recordings. Several QEEG techniques, commonly called "EEG brain mapping," include topographic displays of voltage or frequency, statistical comparisons to normative values, and discriminant analysis. Although much scientific literature has been produced after decades of research in this field, there remains controversy about the clinical role of QEEG analysis techniques. This assessment is meant to help the clinician by providing an expert review of the current clinical usefulness of these techniques.

Evaluation process. Previous assessments on this subject were published by the American Electroencephalographic Society (American EEG Society, AEEGS) in 1987 and by the American Academy of Neurology (AAN) in 1989.,.$^{1,2}$ Members of both societies were notified by newsletter to solicit their opinions with supporting information for this assessment. Commercial digital EEG vendors were identified by their participation in society meeting exhibits or by their known interests in this field, and they were asked to submit relevant scientific publications supporting clinical use. Many experts in the field were also contacted to request their opinions and to cite relevant scientific publications. A literature search was conducted using the Medline database, covering the years 1984-1995. Searched topics included EEG and evoked potentials, among others, and the identified citations were manually screened for relevance to this assessment. Review articles and published literature reference sections were also screened for relevant information. When outside reviewers and other experts presented viewpoints differing from circulated drafts of this assessment, their opinions and relevant cited literature were reviewed and any appropriate changes were made in the assessment.

In assessing the literature, clinical assessment criteria should include several ideal elements and concept $^{3-32}$ : The disease studied should be clearly defined. Criteria for test abnormality should be defined explicitly, clearly, and prospectively. Control groups should be used, including normal controls as well as patients with other diseases in the common differential diagnosis of the disease tested. The control groups should be different from those originally used to derive the test's normal limits. The severity of disease should simulate the severity in patients for which the use of the test is proposed. Test-retest reliability should be high. Various assessments of validity should be measured, e.g., sensitivity, specificity, positive predictive value, and negative predictive value. Validity measures for the evaluated test should be compared to such results obtained with other tests already clinically used in that differential diagnosis, including diagnosis based on signs and symptoms, routine EEG, or neuroimaging tests. Blinded observations were considered a more objective, preferred measure of a test's validity. Medical efficacy was evaluated in several ways. An effective test may reduce morbidity or mortality by clarifying

*Formerly the American Electroencephalographic Society.

From the Department of Clinical Neurophysiology (Dr. Nuwer, Department Head), UCLA Medical Center, Reed Neurological Research Center, Los Angeles, CA.

See page 285 for panel, subcommittee, and committee members.

Approved by the American Clinical Neurophysiology Society Council, September 1996. Approved by the American Academy of Neurology Executive Board, October 1996.

Received January 10, 1997. Accepted in final form January 16, 1997.

Address correspondence and reprint requests to the Therapeutics and Technology Assessment Subcommittee, American Academy of Neurology, 2221 University Avenue SE, Suite 335, Minneapolis, MN 55414. 
which medical intervention is best. It may substitute a less risky test for one with greater medical complications. It may substantially clarify a diagnosis, leading to more accurate prognosis, or improved expectations and behavior. Incremental changes to already accepted tests and applications require less proof through new studies, whereas novel techniques and applications require a greater degree of demonstration of validity and utility.

A panel of experts, jointly appointed by the American Clinical Neurophysiology Society (ACNS, formerly the American EEG Society) and the American Academy of Neurology, reviewed and summarized the relevant literature. The assessment cites some of the reviewed literature, but does not attempt to cite all QEEG literature comprehensively here. Specific panel members reviewed individual topics in detail as well as drafts of the overall assessment. Scientific evidence was weighed based on the classes of evidence, including criteria elements described above. Strengths of recommendations were based on quality and consistency of the clinical scientific evidence as well as the magnitude of the medical efficacy and costs. Possible conflict of interest by study authors was also considered in cases where the authors were involved in commercializing their techniques.

Eventually a draft of this assessment was circulated to many experts in the field, a group of practicing neurologists, and other societies. Their advice about the assessment was taken into consideration in preparation of the final draft of the document.

Various gold standards were considered, depending on the clinical question for which a test was being evaluated. This assessment covered a wide variety of clinical settings. QEEG is inseparably bound together with routine EEG. These two often needed to be considered together for the purposes of the assessment, sometimes specifically assessing whether QEEG offers net advantages over routine EEG in existing diagnostic paradigms. Where routine EEG is not now a part of the usual diagnostic evaluation, the results of QEEG studies were compared against the existing standards for those diagnoses, e.g., using signs, symptoms, neuroimaging results, etc.

General comments and nomenclature. Terms in use in this field include "digital," "paperless," and "quantitative EEG" as well as "EEG brain mapping." The table describes relationships among these various terms.

I. Digital EEG is the paperless acquisition and recording of the EEG via computer-based instrumentation, with waveform storage in a digital format on electronic media, and waveform display on an electronic monitor or other computer output device. The recording parameters and conduct of the test are governed by the applicable standards of the ACNS guidelines and are identical to or directly analogous to those for paper EEG recordings. ${ }^{33}$
Table Nomenclature for digital and quantitative EEG

Digital EEG
Quantitative EEG (QEEG)
Signal analysis
Automated event detection
Monitoring and trending
Source analysis
Frequency analysis
Topographic displays ("brain maps")
Statistical analysis
Comparisons to normative values
Diagnostic discriminant analysis

Ideally, digital EEG creates a recording on a digital medium without loss of anything except the paper itself. In practice, there may be some loss of detail especially at the lower sensitivity settings. Digital EEG also allows for simple but extremely useful digital utilities such as post hoc changes in filters, horizontal and vertical display scale, and montage reformatting that allow greater flexibility in reading the EEG. These tools allow for better visual reading of the record than can be achieved with an analog paper record. Network storage allows access from remote sites. New improved derived references can be calculated and used, and very large numbers of recording channels can be processed and managed. ${ }^{34}$ Digital EEG is an excellent technical advance and should be considered an established guideline for clinical EEG.

II. Quantitative EEG (QEEG) is the mathematical processing of digitally recorded EEG in order to highlight specific waveform components, transform the EEG into a format or domain that elucidates relevant information, or associate numerical results with the EEG data for subsequent review or comparison.

II.A. Signal analysis is the quantitative measurement of specific EEG properties or a transformation of the raw, digitally recorded EEG signal into numerical parameters other than the traditional amplitude versus time. Several types of measurements or analyses can be made.

II.A.1. Automated event detection is the use of mathematical algorithms to detect or identify events or abnormalities that the computer has been instructed to bring to the attention of medical personnel. No alteration is made in the raw EEG data, except optional data compression. This is used typically in long-term EEG recordings for spike and seizure detection.

II.A.2. Monitoring and trending EEG. This technique uses mathematical algorithms to extract parameters from the raw data that summarize the important aspects of the EEG. The medical personnel can then be presented with simplified graphical dis- 
plays of these trended parameters. Alterations of the trends may prompt the users to review in detail specific portions of EEG data. This is used typically in neurophysiologic monitoring applications in the OR or ICU.

II.A.3. Source analysis is a form of mathematical analysis in which the recorded EEG values (typically scalp voltage values from an epileptiform abnormality) are compared with predetermined models of possible EEG generators. The analysis may specify the location, orientation, strength, and number of the possible sources of the analyzed spike or other EEG feature.

II.A.4. Frequency analysis converts the original EEG data into a representation of its frequency content. The magnitude corresponds to the amount of energy that the original EEG possesses at each frequency. An example of the use of frequency analysis is to look for evidence of excess slow activity. Coherence analysis uses calculations similar to frequency analysis to obtain information about the temporal relationships of frequency components at different recording sites, typically for evaluation of seizure origin. The results of signal processing, such as frequency analysis, may be displayed as a table of numbers, a multidimensional graph, or a topographic display (see below).

II.B. Topographic EEG displays can present visually a spatial representation of raw EEG data (i.e., voltage amplitude) or a derived parameter (e.g. power in a given frequency band, or peak latency). Typically, the parameter under study is mapped onto a stylized picture of the head or the brain, but may be mapped onto an anatomically accurate rendering of the brain, such as a three-dimensional volumereconstructed MRI. Amplitude at a given anatomic site is ordinarily represented as a color or intensity, and amplitudes at unmeasured sites are interpolated to present a smooth display. These displays can highlight some spatial features of the EEG. These representations are often collectively referred to as EEG brain maps. This term, in this context, should not be confused with functional cortical brain mapping by direct electrical cortical stimulation or with brain mapping by neuroimaging techniques, which have no direct relationship to EEG brain mapping.

II.C. Statistical analysis compares variables derived from the digitally recorded EEG between groups of people or between a patient and a group. These comparisons may be carried out on individual variables (e.g., the alpha frequency) or on many variables using appropriate multifactorial statistical methods. Spatial aspects may be included, e.g., by statistical comparison of topographic EEG maps.

II.C.1. Comparison to normative values uses group statistics to determine whether a parameter (or parameters) measured on an individual patient lies inside or outside the range of normal values. Statistical techniques employed may be simple thresholds based on the mean and standard deviation of a "nor- mal" distribution. More advanced techniques may encompass age-adjusted norms, bayesian statistics, etc.

II.C.2. Diagnostic discriminant analysis gathers selected parameters for several different patient diagnostic subgroups, as well as for controls. A discriminant function can be mathematically determined that ascribes certain patterns of these parameters to each patient group. The technique then compares the pattern of the EEG parameters derived from one patient to all of the relevant patient groups to determine with which diagnostic group the patient's EEG is statistically most closely associated.

Problems. Despite such potential advantages, QEEG's clinical usefulness is now quite limited, although it has substantial potential for future applications. At this time, most scientific reports more convincingly have demonstrated research applications rather than clinical applications. Among the reports suggesting clinical utility, few have been prospectively verified or reproduced, and some conflict with others. Techniques used in QEEG vary substantially between laboratories, and any clinical usefulness found with one specific technique may not apply when using a different technique. Many technical and clinical problems interfere with simple clinical application. Traditional EEG artifacts can appear in unusual and surprising ways, and new artifacts can be caused by the data-processing algorithms. Some artifacts, such as eye movements, are common in the EEG, and even subtle ones will produce highly significant QEEG abnormalities if they go unrecognized. Abnormal activity such as epileptiform spikes may be overlooked, considered artifactual, or misinterpreted. Transient slowing can be missed. The computer may score as "abnormal" some EEG activity known to have no clinical importance, such as $\mathrm{mu}$, or slow alpha variant.

Automated assessment of normality must take into account the subject's age, state of alertness, and other facts. But, ways to accomplish this are not yet well defined in any way that has been widely accepted or consistently applied. These problems are compounded when the patient is receiving medication that alters the EEG. Substantial unresolved statistical issues are critical in automated assessment of normality. Because of these problems, EEG brain mapping and other QEEG techniques are very predisposed to false-positive errors, i.e., erroneously identifying normal or normal variant patterns as "abnormalities." Experienced users are aware of these problems, which represent challenges especially for less-experienced interpreters. These difficulties have been reviewed elsewhere, along with the controversy about their impact on potential clinical utility. ${ }^{35-57}$

Prospective evaluation of EEG discriminant analysis has not yet demonstrated its practical use in clinical differential diagnosis. Some studies have 
shown very interesting positive results, but these still await prospective assessment of clinical utility. Substantial variability in EEG features occurs among normal subjects as well as among patients with specific disorders, so that the discriminant matching of EEG features may be very difficult in practice. Mistaken diagnoses can readily occur in such QEEG discriminant analyses. ${ }^{58}$ When drowsiness occurs, or if the patient is taking certain medications, the tests are invalid. Drowsiness can mimic disease in EEG or QEEG. Even well-established routine EEG abnormalities such as focal slowing are generally nonspecific as to cause or disease.

A common mistake occurs when running a large battery of QEEG tests, sometimes encompassing hundreds or even thousands of individual statistical assessments on one patient. In this setting, many statistically positive "abnormalities" will occur by chance alone in normal subjects. These false-positive "abnormalities" average about $5 \%$ of the number of statistical tests run in some applications, but can reach 15 to $20 \%$ in some individual normal control subjects. ${ }^{59}$ Many changes seen statistically are generally now regarded as clinically meaningless, e.g., diffusely decreased delta or increased beta. Others are controversial and still have no well-established clinical role, e.g., changes in coherence. Some retrospective and statistical analyses of coherence have shown interesting, positive results that await prospective validation in clinical practice. Given the complexity of studies or tests with very large volumes of statistical testing, some of these problems may be avoided by using QEEG techniques to ask a few specific measurement questions that are likely to be clinically meaningful, e.g., to localize or identify increases in slow-wave activity.

Many common QEEG mistakes have been reviewed by Duffy et al., ${ }^{46}$ along with recommendations for controlling some of the difficulties. That review expresses some overly optimistic opinions about the clinical utility of QEEG. In general, the review's many specific technical suggestions and precautions are quite appropriate.

Visual and auditory long-latency evoked potentials have also been used along with EEG brain mapping techniques. ${ }^{60-81}$ At present, insufficient information is available about evoked potential topographic mapping and statistical normative scoring to assess its normal variants, normal limits, effects of medication, and other relevant technical and patientrelated factors. No well-designed, prospectively verified clinical studies have demonstrated the clinical utility of topographic mapping of long-latency evoked potentials for diagnosis in clinical settings. When statistical methods (e.g., z-scores) do detect changes in topographic maps of long-latency EP amplitudes, the reader may not be able to differentiate between chance events, normal variants, and true pathology.

Overall, the problems of QEEG were weighed against its positive values. In some circumstances,
QEEG has some positive values, but they are outweighed by the substantial problems encountered in trying to use the tests clinically. In other circumstances, QEEG's positive values outweighed its disadvantages, leading to positive recommendations for use. In the latter case, these positive values outweigh the technique's problems only when used in expert hands and with good clinical judgment.

Clinical settings. Epilepsy. Routine EEG is an established test commonly used in the clinical evaluation of patients with epilepsy. EEG testing can help to locate an epileptic focus or suggest the type of epilepsy. Some QEEG methods have built on that established role. Routine EEG, EEG brain mapping, and other QEEG techniques cannot diagnose whether a patient has epilepsy.

Spike and seizure detection. Digital spike and seizure detection can identify candidate events that might be epileptic spikes or seizures, although frequent false-positive detections occur. The clinical use of any spike or seizure-dection algorithm must balance sensitivity against specificity. In long-term EEG monitoring records of outpatients, inpatients, or ICU patients, candidate spikes or seizure events are selected automatically and saved for subsequent professional visual review and confirmation. This data reduction method is a valuable time-saving tool, especially in recordings lasting one or several days. Studies ${ }^{82-104}$ include multiple well-designed, controlled studies comparing digital detection to detection by visual review as the standard. Sensitivities were often better than 80 to $90 \%$, although specificity remained poor. The clinical rationale seems clear. General clinical use in the community has been very positive.

Such monitoring and automated seizure detection can also identify nonconvulsive seizures occurring among ICU patients at risk for such complications, prompting early clinical intervention..$^{98-100,105}$ For ICU patients requiring neuromuscular blockade while intubated, EEG monitoring may be the only way to detect convulsive status epilepticus. ${ }^{106}$ Nonconvulsive seizures can also present with a diminished state of consciousness, potentially mimicking other types of encephalopathy. ${ }^{107-113}$

Spike dipole analysis. Quantitative analysis of the spatial and temporal character of spike voltage fields and subsequent equivalent dipole modeling can suggest the location of the cortical generators, the presence and direction of propagation, and the existence of multiple separate spike sources. While sometimes available from routine visual review of EEG traces, this information can be estimated more confidently by combining visual review with voltage mapping and source modeling of individual or averaged spikes. Although dipole solutions obtained are not mathematically unique and the localization is not anatomically precise, these techniques appear 
useful in the noninvasive evaluation of candidates for epilepsy surgery. In particular, certain characteristic scalp voltage fields of epileptic spikes and ictal discharges are likely to have a mesial-basal temporal source, whereas other fields are likely to have a lateral temporal cortical origin. ${ }^{144-121}$ If a sufficient area of the mesial-basal temporal cortex is involved in generating a spike discharge, the discharge can be recorded at the scalp whereas smaller mesial-basal spike discharges may not be accompanied by distinguishable scalp fields. ${ }^{122}$ Caution must be exercised because erroneous localization can occur even for experienced users due in large part to the simplified spherical head model commonly used. ${ }^{123}$ The welldesigned studies of this specific technique are few but consistent and confirmed in follow-up postoperatively. The clinical rationale seems clear. Control testing for evoked potential known cortical generator sites has confirmed the technical accuracy of dipole localization. The use of dipole analysis seems sufficiently demonstrated to warrant its clinical use in patients undergoing evaluation for surgical therapy for epilepsy.

In other clinical settings, it has not been demonstrated to be sufficiently clinically useful to warrant general clinical use at this time. In benign rolandic epilepsy of childhood (BREC), quantitative spike voltage analysis can determine field complexity and dipole model stability. These data have shown diagnostic value in differentiating "typical" from "atypical" BREC and complex partial epilepsy, a distinction that carries substantial prognostic and therapeutic significance. ${ }^{124-127}$ Here, though, the clinical use is somewhat unclear overall. Further follow-up studies seem warranted on these other uses of dipole analysis, to clarify the prospective clinical utility and the reliable impact, if any, on patient care management or counseling.

Secondary bilateral synchrony, Some quantitative techniques can help differentiate primary generalized discharges from secondary bilateral synchrony by looking for small, reproducible interhemispheric timing differences in such discharges and the characteristic distribution of maximal activity. ${ }^{128-132}$ This differentiation may help guide the choice of the best antiepileptic medication as well as aid presurgical localization. This potentially useful application has not yet been demonstrated to be sufficiently clinically useful to warrant general clinical use.

Frequency analysis and fast activity. Regional or focal EEG slowing or diminished fast background activity has long been valued as a means to help lateralize an epileptic focus. Quantitative frequency analysis can occasionally identify and lateralize or localize EEG features that are subtle and might be overlooked on routine visual EEG inspection. ${ }^{71,72,133-137}$ Attempts to use evoked potentials for lateralization have met with mixed success, and this is not yet sufficiently reliable for routine clinical use. $^{71-72,138}$ In recordings from implanted electrodes, digital EEG with a high sampling rate and high filters above $150 \mathrm{~Hz}$ can highlight very high frequency activity, ${ }^{139-141}$ which can be difficult to detect on traditional paper EEG recording. Interpretation of these slow and fast rhythms would be considered a part of the interpretation of the digital EEG per se, rather than a separate diagnostic procedure.

Overall, on the basis of Class II evidence and several Class I studies, QEEG is considered an established adjunct to digital EEG for screening for possible spikes or seizures in long-term monitoring and ambulatory recording, to facilitate subsequent expert visual EEG interpretation.

QEEG topographic voltage analysis with dipole analysis may be useful in pre-surgical evaluations as an addition to digital EEG (Class II evidence, as a possibly useful test).

Cerebrovascular disease. In cerebrovascular disease, several EEG frequency parameters are highly correlated with regional blood flow or metabolism. When used by skilled professionals experienced in EEG interpretation, sensitivity and specificity are high for detection of ischemia-related cerebral impairment or similar focal impairment. ${ }^{142-157}$ These studies show sensitivity generally greater than $80 \%$ with good specificities, false-positive rates below 5 to $10 \%$, and correlations of $r>0.7$ between EEG and blood flow in ischemic and nonischemic regions. Many were controlled, well-designed studies, some of which were prospective and blinded and which showed that QEEG could detect reliable focal features that were missed on initial visual review of the routine EEG. These tests can be quite abnormal even when the CT is still normal, such as in the first 1 to 3 days after stroke or when the degree of ischemia is mild enough to cause dysfunction without infarction. However, EEG anatomical localization is very much inferior to that found with CT or MRI. As with routine EEG, QEEG changes are unable to differentiate infarction from hemorrhage, tumor, or other focal cerebral lesions. ${ }^{158}$ Little has been published on how these QEEG tests could affect the diagnosis or treatment of individual patients. For most patients with cerebrovascular disease, CT or MRI remains the test of choice. In general, therefore, QEEG has no clear medical indication in evaluations of patients with cerebrovascular disease when MRI, $\mathrm{CT}$, and routine EEG are already available but are nonlocalizing or noncontributory. Exceptions warranting possible EEG, with or without QEEG, are certain patients for whom MRI or CT is not available in their community; or patients who are too ill to travel to a neuroimaging location; or patients in whom the neuroimaging tests are nonlocalizing, but substantial clinical suspicion of focal cerebral dysfunction remains. EEG is clinically warranted among some cerebrovascular disease patients who have additional clinical problems or complications such as coma or possible seizures.

Based on Class II and III evidence, QEEG in expert hands may possibly be useful in evaluating cer- 
tain patients with symptoms of cerebrovascular disease whose neuroimaging and routine EEG studies are not conclusive (Type $B$ recommendation).

Monitoring in the $O R$ and ICU. In continuous OR or ICU monitoring, such as during carotid endarterectomy, continuous trending of EEG frequency analysis may supplement routine EEG to identify and to measure clinically meaningful changes more reliably. ${ }^{159-161}$ Trending can graphically demonstrate physiologic changes in a way that is sometimes easier to appreciate, especially when seeking gradual change over very long time periods.

For ICU patients at high risk for ischemic stroke, acute intracranial bleed, vasospasm, critically elevated intracranial pressure (ICP), or related ischemia, continuous monitoring of EEG has been used. Monitoring can identify complications in time to initiate therapy, thereby preventing some long-term neurologic sequelae. It can also provide feedback on therapy, allowing titration of barbiturates given for deliberate burst-suppression, antiepileptics given for nonconvulsive status, mannitol given for increased ICP or other therapeutic interventions. Quantitative monitoring may also help to separate variablereactive EEG from monotonous-nonreactive EEG, thereby substantially enhancing accuracy of prognosis. In the ICU, such EEG monitoring often uses frequency analysis trends to supplement the routine analog or digital EEG collection, allowing quick identification of changes from trends while retaining the original digital EEG tracings for interpretation by an experienced EEG reader. Such uses have been verified in several large prospective trials and other studies. ${ }^{98-100,162-183}$ Many of these are well-designed studies clearly demonstrating clinically useful results not obtainable in any other way. Continuous monitoring of the brain in this way is able to detect some types of common neuro-ICU comphications, such as nonconvulsive status epilepticus or early ischemia, which would not be detected and diagnosed by occasional 20-minute-long routine EEGs or careful clinical neurologic examination or neuroimaging tests. Long-term follow-up studies demonstrated very substantial outcome differences predicted by EEG monitoring. The clinical rationale for use of these techniques seems clear.

On the basis of considerable Class II evidence, EEG seizure detection and frequency analysis is considered established as a practice option when used as an adjunct to routine or digital EEG for continuous brain monitoring by frequency trending in the $\mathrm{OR}$ or ICU to detect early acute intracranial complications, and for screening for possible epileptic seizures in high-risk ICU patients (Type B recommendation).

Dementia and encephalopathies. In dementia evaluations, the finding of focal or generalized EEG background slowing does strongly suggest an organic basis rather than depression. QEEG parallels the long-established role for routine EEG in the detection of diminished alpha and increased slowing in delirium and dementias. EEG frequency analysis sometimes allows confident detection of excess slowing to be appreciated and measured more readily than does routine EEG alone. ${ }^{184-208}$

EEG frequency analysis tests cannot yet reliably distinguish between the types of dementia, in contrast to some specific routine EEG wave patterns that are highly suggestive of certain encephalopathies or dementing disorders. Most EEG changes in dementia can be seen on routine EEG testing, and so the additional clinical usefulness of QEEG remains limited. The sensitivity of EEG, with or without frequency analysis, is high for moderate-to-severe dementia, and the degree of QEEG or routine EEG abnormality corresponds to the degree of dementia and likelihood of disease progression. Neural net classifiers have met with initial success in separating patients with mild-moderate Alzheimer's disease from normal controls, ${ }^{209}$ or a mixed group of patients with dementias from normal controls, ${ }^{210}$ but these tools still require prospective testing in actual clinical situations. In one study, EEG frequency analysis along with positron emission tomography (PET) gave better diagnostic sensitivity for dementia than did either test alone. ${ }^{211}$ Changes in EEG coherence also have been reported in dementias, ${ }^{204,212,213}$ but there is not yet a prospective validation of clinical utility for coherence testing, nor a resolution of the question about whether this provides any useful information beyond the known frequency analysis changes per se. The clinical role for QEEG frequency analysis is limited to patients for whom the possibility of dementia remains an unresolved clinical problem even after an appropriate history and physical examination, and after obtaining neuroimaging testing, blood work, or routine EEG as appropriate for evaluation of dementia. For such patients, increased relative theta or other specific slowing may be due to an organic disorder of memory and cognition, as opposed to depression, anxiety, or other causes of the cognitive complaints.

Latency delay in the P300 long-latency auditory evoked potential, without topographic mapping, has been found useful for detection of dementias such as Alzheimer's disease. ${ }^{204,214-216}$ The P300 is useful when the organic nature of cognitive complaints remains in question after routine examinations and tests have been carried out. The P300 latency delays are strongly correlated with PET hypometabolism in early Alzheimer's. ${ }^{217}$ In early Alzheimer's disease, the P300 may also show a selective loss of the posterior scalp components. ${ }^{218,219}$ Multichannel P300 recordings with topographic mapping may help clarify scalp potential distributions and help to separate the P300 waves from eyeblink artifact, alpha waves, or other confounding factors. Topographic P300 changes have been observed in a wide variety of disorders $^{220}$ and so are still considered nonspecific in nature. As such, P300 latency delay remains the accepted criteria for assessing abnormality in P300 testing, even when multichannel recording is used.

The degree of slow EEG activity quantified by fre- 
quency analysis does correspond to the degree of hepatic encephalopathy ${ }^{221-224}$ and is predictive of longterm outcome with or without liver transplantation. However, clinical usefulness in this setting remains unclear because QEEG results rarely influence clinical management, and because a large number of other factors influence and predict outcome.

Routine EEG has a role in some psychiatric evaluations. ${ }^{225}$ EEG can identify slow wave or epileptiform abnormalities, which may occur in delirium, dementia, intoxication, and other syndromes involving gross central nervous system impairment. ${ }^{226} \mathrm{Ex}$ cept as described above, the addition of quantitative analysis (QEEG) has not yet been demonstrated to have value beyond that of routine EEG.

Overall, routine EEG has long been an established test used in evaluations of dementia and encephalopathy when the diagnosis remains unresolved after initial clinical evaluation. Based on Class II and III evidence, QEEG in expert hands may possibly be useful in evaluating certain patients with dementia or encephalopathy whose neuroimaging and routine EEG studies are not conclusive (Type $B$ recommendation).

Head injury. Several published studies have addressed EEG brain mapping and other QEEG analysis techniques in patients with head injury. Some reports are uncontrolled, unblinded, or retrospective observations, which are difficult to use for assessing clinical utility. ${ }^{227-230}$ Patients with extensive traumatic lesions, obvious on neuroimaging studies, had EEG and QEEG abnormalities, a finding that is not surprising. ${ }^{331}$ In one small group of patients with postconcussion syndrome, an increase in 8 to $10 \mathrm{~Hz}$ alpha was reported. ${ }^{232} \mathrm{~A}$ subsequent report described reduced alpha in a much larger group of patients after mild head injury. In the latter study, mildhead-injury patients were separated from controls using a bayesian statistical discriminant formula weighted toward measurements of coherence and phase relationships as well as posterior alpha and frontotemporal beta activity. The authors were able to replicate their findings with good sensitivity and specificity. ${ }^{233,234}$ Others have commented that this technique is predisposed to false-positive "abnormalities" in normal subjects due to mild drowsiness or other problems. Further validation would be helpful, especially from investigators not involved in the commercialization of this technique.

In coma due to severe head injury, EEG monitoring, with or without frequency analysis trending, has been shown to predict outcome with a useful degree of reliability and to detect nonconvulsive seizures or other complications. ${ }^{98-100,164-178,183,235-241}$

Based on the available published literature, EEG brain mapping and other QEEG techniques have been reported to show very interesting changes in some studies. However, evidence of clinical usefulness or consistency of results are not considered sufficient for us to support its use in diagnosis of patients with postconcussion syndrome, or minor or moderate head injury. In acute severe head injury, EEG testing or monitoring for seizures or other complications can be clinically helpful for diagnosis and prognosis.

Learning and attention disorders. Neurophysiologic studies of children with learning and attention disorders have shown that poor spellers, children with dyslexia, or hyperactive children have different neurophysiologic responses from those in groups of normal children. ${ }^{242-261}$ Relationships between a patient's EEG patterns and outcome of therapy have been proposed, ${ }^{262}$ but still await a controlled verification. This research has been useful for scientific understanding of physical and physiologic differences between children with these disorders and normal children, although the studies vary in the kinds of changes reported and there have been questions raised about reproducibility. ${ }^{263}$ Diagnostic tests, including EEG brain mapping, have not been proven useful in establishing the diagnosis or treatment plan for individual children. No independent blinded comparisons have been made with a clinical standard. Many studies do not use an appropriate spectrum of patients for whom the diagnostic tests would be applied in clinical practice. There is no evidence that outcome was changed by the diagnostic testing or by the treatment plans predicated on such testing. As a result, there is no evidence that patients are better off for having had these tests performed.

EEG is indicated whenever epilepsy is suspected. Additional scientific investigation of neurophysiologic changes in children with learning and attention problems is needed to follow up on these very interesting reports. However, at this time we cannot recommend QEEG as a test diagnosing learning disability or attention disorder, assisting with counseling, or providing the basis for treatment decisions for these children.

Other disorders. There have been a large number of very interesting reports using various QEEG techniques in the scientific evaluation of patients with tumors, multiple sclerosis, migraine, solvent exposure, radiation exposure, chronic pain, Tourette's syndrome, multiple personality, schizophrenia, panic disorder, depression, alcoholism, and drug abuse. ${ }^{59,264-309}$ Some research studies have shown reproducible differences between groups of patients and groups of normal subjects, e.g., increased frontal alpha in depression and substance abuse. Studies of individual patient results were often not truly prospective. In many studies, it was difficult to assess the potential impact of the author's potential commercial conflict of interest in these techniques. Progress is being made in the scientific understanding of cerebral dysfunction in some of these disorders, and the relationships of QEEG features to other clinical aspects of these disorders. However, these scientific observations are not necessarily directly relevant for clinical diagnosis in individual patient care situations.

The specific ways for the clinician to use this 
QEEG information in individual clinical patient care is not yet generally regarded as clear or well demonstrated. If routine EEG, EEG brain mapping, or other QEEG is done in any of those settings and an abnormality is found, the abnormality may raise the question of an organic impairment, but it is not specific for a particular cause or type of pathology and may not correspond to any patient symptom. Careful correlation of the routine EEG findings with the clinical problem is required for interpretation of any such abnormality.

The American Psychiatric Association (APA) Task Force on Quantitative Electrophysiological Assessment $^{226}$ has concluded that QEEG can help detect excess slow activity in organic disorders such as dementia. However, they also concluded that QEEG is not yet able to help in the diagnosis of other disorders, such as schizophrenia or depression. They further emphasized that the ability of any QEEG procedure to make psychiatric diagnoses or to discriminate between various groups of psychiatric patients and normal subjects is not well established. We agree with these APA recommendations.

At this time, the clinical use of these QEEG tests remains under investigation for these clinical settings beyond the dementias.

Medical-legal abuse. In some trial law and insurance circulars and advertisements, EEG brain mapping and other QEEG techniques have been cited as reliable tests. ${ }^{310} \mathrm{~A}$ major disadvantage of these tests in legal disputes is the occurrence of false-positive results, i.e., "abnormal" results in normal subjects and incorrect diagnoses in patients. ${ }^{58,59}$ Results also can be dramatically altered during the subjective process of selecting portions of an EEG for quantitative analysis. There are no objective safeguards to prevent statistical or unintended errors. Probative value and even the test-retest reproducibility can be poor. There is great potential for abuse.

When statistical testing is used to compare a patient to a normative database, statistical "abnormalities" detected may be clinically meaningless. Some normal variant EEG waveshapes are statistically "unusual" but have no known clinical significance. Automated QEEG processes fail to take this into account, and instead flag these EEG features as "abnormal."

The use of these techniques to support one side or the other in court proceedings can readily result in confusion, abuse, and false impressions. ${ }^{311}$ These are contrary to the qualities cited as suitable for scientific evidence used in the courtroom. ${ }^{312-315}$ Indeed, these problems and a lack of general acceptance were cited in state and federal court decisions disallowing the use of EEG brain mapping as evidence, under the older Frye rules and under the recent Daubert rules. ${ }^{316-320}$

On the basis of clinical and scientific evidence, opinions of most experts, and the technical and methodologic shortcomings, QEEG is not recom- mended for use in civil or criminal judicial proceedings.

Conditions for clinical use. Any clinical use of digital EEG must be a direct extension of routine EEG testing. The actual EEG polygraph waveforms must be preserved on paper or in magnetic or optical storage. For multiple-day monitoring, e.g., epilepsy long-term monitoring, only selected portions of the record are stored after the data are reviewed and interpreted as needed. They must be available for others to review clinically as needed. These EEG tracings must be interpreted thoroughly before it is possible to interpret the quantified analysis. The technical quality of these EEG recordings must be satisfactory for purposes of clinical interpretation, according to accepted guidelines, i.e., the American EEG Society Guidelines in $\mathrm{EEG}^{33,321-323}$ and the International Federation of Clinical Neurophysiology Recommendations for the Practice of Clinical Neurophysiology. ${ }^{324,325}$ At present, there is no clinical application for clinical QEEG analysis without analysis of the accompanying routine EEG. The combined EEG and quantitative analysis should be interpreted only by physicians with appropriate training, skills, knowledge, and abilities in routine EEG, as well as additional knowledge and experience with the relevant additional technical problems, artifacts, normal variants, and statistical issues encountered in QEEG.

EEG brain mapping and other QEEG are often very misleading, particularly in the hands of practitioners with limited skills, knowledge, abilities, training, and experience in EEG interpretation.

Summary. A. Digital EEG is an established substitute for recording, reviewing, and storing a paper EEG record. It is a clear technical advance over previous paper methods. It is highly recommended. (Class III evidence, Type $\mathrm{C}$ recommendation)

B. EEG brain mapping and other advanced QEEG techniques should be used only by physicians highly skilled in clinical EEG, and only as an adjunct to and in conjunction with traditional EEG interpretation. These tests may be clinically useful only for patients who have been well selected on the basis of their clinical presentation.

C. Certain quantitative EEG techniques are considered established as an addition to digital EEG in:

C.1. Epilepsy: For screening for possible epileptic spikes or seizures in long-term EEG monitoring or ambulatory recording to facilitate subsequent expert visual EEG interpretation. (Class I and II evidence, Type A recommendation as a practice guideline)

C.2. OR and ICU monitoring: For continuous EEG monitoring by frequency-trending to detect early, acute intracranial complications in the OR or ICU, and for screening for possible epileptic seizures in high-risk ICU patients. 
(Class II evidence, Type B recommendation as a practice option)

D. Certain quantitative EEG techniques are considered possibly useful practice options as an addition to digital EEG in:

D.1. Epilepsy: For topographic voltage and dipole analysis in presurgical evaluations. (Class II evidence, Type B recommendation)

D.2. Cerebrovascular Disease: Based on Class II and III evidence, QEEG in expert hands may possibly be useful in evaluating certain patients with symptoms of cerebrovascular disease whose neuroimaging and routine EEG studies are not conclusive. (Type $B$ recommendation)

D.3. Dementia: Routine EEG has long been an established test used in evaluations of dementia and encephalopathy when the diagnosis remains unresolved after initial clinical evaluation. In occasional clinical evaluations, QEEG frequency analysis may be a useful adjunct to interpretation of the routine EEG when used in expert hands. (Class II and III evidence as a possibly useful test, Type B recommendation)

E. On the basis of current clinical literature, opinions of most experts, and proposed rationales for their use, QEEG remains investigational for clinical use in postconcussion syndrome, mild or moderate head injury, learning disability, attention disorders, schizophrenia, depression, alcoholism, and drug abuse. (Class II and III evidence, Type D recommendation)

F. On the basis of clinical and scientific evidence, opinions of most experts, and the technical and methodologic shortcomings, QEEG is not recommended for use in civil or criminal judicial proceedings. (Strong Class III evidence, Type E recommendation)

G. Because of the very substantial risk of erroneous interpretations, it is unacceptable for any EEG brain mapping or other QEEG techniques to be used clinically by those who are not physicians highly skilled in clinical EEG interpretation. (Strong Class III evidence, Type E recommendation)

\section{Acknowledgments}

Other AAN and ACNS committee members participating during the initial year of development include Stanley van den Noort, MD; Paul Altrocchi, MD; Keith Chiappa, MD; Richard Coppola, DSc; and John Hughes, MD, PhD.

Panel of Experts: Marc R. Nuwer, MD, PhD, Panel Chairperson and Senior Author; Richard P. Brenner, MD; Gastone G. Celesia, MD; John Desmedt, MD; John S. Ebersole, MD; Bruce J. Fisch, MD; Michael L. Goldstein, MD; Douglas S. Goodin, MD; Richard N. Harner, MD; Ronald P. Lesser, MD; Fumisuke Matsuo, MD; Ken Nagata, MD; and William W. Sutherling, MD.

American Academy of Neurology Therapeutics and Technology Assessment Subcommittee: John H. Ferguson, MD, Chair; Mitchell Brin, MD; Robert Goldman, MD; Douglas Goodin, MD; Phillip B. Gorelick, MD, MPH; Daniel Hanley, MD; Dale J. Lange, MD; Anne Marie Marini, MD; and E. Steven Roach, MD.

American Clinical Neurophysiology Society Digital EEG Anal ysis Committee: Robert Fisher, MD, PhD, Chairperson; David Blum, MD; Richard Brenner, MD; Richard Burgess, MD; Charles Epstein, MD; Jean Gotman, PhD; Prasanna Jayakar, MD, PhD;
Ronald Lesser, MD; Donald Tucker, PhD; Richard D. Weiner, MD, $\mathrm{PhD}$; and Peter Wong, MD.

Note. This statement is provided as an educational service of the American Academy of Neurology and American Clinical Neurophysiology Society (formerly the American Electroencephalographic Society). It is based on an assessment of current scientific and clinical information. It is not intended to include all possible proper methods of care for a particular neurologic problem or all legitimate criteria for choosing to use a specific procedure. Neither is it intended to exclude any reasonable alternative methodologies. The AAN and ACNS recognize that specific patient care decisions are the prerogative of the patient and the physician caring for the patient, based on all the circumstances involved

\section{DEFINITIONS}

Safety: A judgment of the acceptability of risk in a specified situation, e.g., for a given medical problem, by a provider with specified training, at a specified type of facility.

Effectiveness: Producing a desired effect under conditions of actual use.

Established: Accepted as appropriate by the practicing medical community for the given indication in the specified patient population.

Possibly useful: Given current knowledge, this technology appears to be appropriate for the given indication in the specified patient population. As more experience and long-term follow-up are accumulated, this interim rating will change. This rating is sometimes referred to as promising."

Investigational: Evidence insufficient to determine appropriateness, warrants further study. Use of this technology for given indication in the specified patient population should be confined largely to research protocols.

Doubtful: Given current knowledge, this technology appears to be inappropriate for the given indication in the specified patient population. As more experience and long-term follow-up are accumulated, this interim rating will change.

Unacceptable: Regarded by the practicing medical community as inappropriate for the given indication in the specified patient population.

Strength of Recommendation Ratings

Type A. Strong positive recommendation, based on Class I evidence, or overwhelming Class II evidence.

Type B. Positive recommendation, based on Class II evidence.

Type C. Positive recommendation, based on strong consensus of Class III evidence.

Type D. Negative recommendation, based on inconclusive or conflicting Class II evidence.

Type E. Negative recommendation, based on evidence of ineffectiveness or lack of efficacy.

Standards. Generally accepted principles for patient management that reflect a high degree of clinical certainty (i.e., based on Class I evidence or, when circumstances preclude randomized clinical trials, overwhelming evidence from Class II studies that directly address the question at hand, or from decision-analysis that directly addresses all the issues).

Guidelines. Recommendations for patient management that may identify a particular strategy or range of management strategies that reflect moderate clinical certainty (i.e., based on Class II evidence that directly addresses the issue, decision analysis that directly 
addresses the issue, or strong consensus of Class III evidence).

Practice options or advisories. Other strategies for patient management for which there is some favorable evidence, but for which the community still considers this an option to be decided upon by individual practitioners.

Practice parameters. Results, in the form of one or more specific recommendations, from a scientifically based analysis of a specific clinical problem.

Quality of evidence ratings

Class I. Evidence provided by one or more well-designed, prospective, blinded, controlled clinical studies.

Class II. Evidence provided by one or more well-designed clinical studies such as case control, cohort studies, etc.

Class III. Evidence provided by expert opinion, nonrandomized historical controls or case reports of one or more.

\section{References}

1. American Electroencephalographic Society. American Electroencephalographic Society statement on the clinical use of quantitative EEG. J Clin Neurophysiol 1987;4:197.

2. American Academy of Neurology. Assessment: EEG brain mapping. Report of the American Academy of Neurology, Therapeutics and Technology Assessment Subcommittee. Neurology 1989;39:1100-1101.

3. Wasson JH, Sox HC, Neff RK, Goldman L. Clinical prediction rules: applications and methodological standards. N Engl J Med 1985;313:793-799.

4. Longstreth WT, Koepsell TD, van Belle G. Clinical Neuroepidemiology: I. Diagnosis. Arch Neurol 1987a;44:1091-1099

5. Longstreth WT, Koepsell TD, van Belle G. Clinical Neuroep demiology: II. Outcomes. Arch Neurol 1987b;44:1196-1202.

6. Ransohoff DF, Feinstien AR. Problems of spectrum and bias in evaluating the efficacy of diagnostic tests. N Engl J Med 1978;299:926-930.

7. McMaster University Health Sciences Centre, Department of Clinical Epidemiology and Biostatistics. How to read clinical journals: II. To learn about a diagnostic test. Can Med Assoc J 1981:124:703-710.

8. Sackett DL, Haynes RB, Tugwell P. Clinical epidemiology: a basic science for clinical medicine. Boston: Little, Brown and Company, 1985.

9. Sheps SB, Schechter MT. The assessment of diagnostic tests: a survey of current medical research. JAMA 1984;252:24182422.

10. Guyatt G, Drummond M, Feeny D, et al. Guidelines for the clinical and economic evaluation of health care technologies. Soc Sci Med 1986;22:393-408.

11. Guyatt G, Rennie D, for the evidence-based medicine working group. Users' guides to the medical literature. JAMA 1993:270:2096-2097.

12. Oxman AD, Sackett DL, Guyatt GH, for the evidence-based medicine working group. Users' guides to the medical literature. I. How to get started. JAMA 1993;270:2093-2095.

13. Guyatt GH, Sackett DL, Cook DJ, for the evidence-based medicine working group. Users' guides to the medical literature. II. How to use an article about therapy or prevention. A. Are the results of the study valid? JAMA 1993;270:25982601

14. Guyatt GH, Sackett DL, Cook DJ, for the evidence-based medicine working group. Users' guides to the medical literature. II. How to use an article about therapy or prevention. $B$. What were the results and will they help me in caring for my patients? JAMA $1994 ; 271: 59-63$.

15. Jaeschke R, Guyatt GH, Sackett DL, for the evidence-based medicine working group. Users' guides to the medical literature. III. How to use an article about a diagnostic test. A. Are the results of the study valid? JAMA 1994;271:389-291.

16. Jaeschke R, Guyatt GH, Sackett DL, for the evidence-based medicine working group. Users' guides to the medical litera- ture. III. How to use an article about a diagnostic test. B What are the results and will they help me in caring for my patients? JAMA 1994;271:703-707.

17. Levine M, Walter S, Lee $\mathbf{H}$, Haines $T$, Holbrook A, Moyer V, for the evidence-based medicine working group. Users guides to the medical literature. IV. How to use an article about harm. JAMA 1994;271:1615-1619.

18. Laupacis A, Wells G, Richardson S, Tugwell P, for the evidence-based medicine working group. Users' guides to the medical literature. V. How to use an article about prognosis. JAMA 1994;272:234-237

19. Oxman AD, Cook DJ, Guyatt GH, for the evidence-based medicine working group. Users' guides to the medical literature. VI. How to use an overview. JAMA 1994;272:1367-1371.

20. Richardson S, Detsky AS, for the evidence-based medicine working group. Users' guides to the medical literature. VII. How to use a clinical decision analysis. A. Are the results of the study valid? JAMA 1995;273:1292-1295.

21. Richardson S, Detsky AS, for the evidence-based medicine working group. Users' guides to the medical literature. VII. How to use a clinical decision analysis. B. What are the results and will they help me in caring for my patients? JAMA 1995;273:1610-1613.

22. Hayward RSA, Wilson MC, Tunis SR, Bass EB, Guyatt G, for the evidence-based medicine working group. Users' guides to the medical literature. VIII. How to use clinical practice guidelines. A. Are the recommendations valid? JAMA 1995; 274:570-574

23. Wilson MC, Hayward RSA, Tunis SR, Bass EB, Guyatt G, for the exidence-based medicine working group. Users' guides to the medical literature. VIII. How to use clinical practice guidelines. $\mathrm{B}$. What are the recommendations and will they help you in caring for your patients? JAMA 1995;274:1630-

24. Guyatt G, Sackett DI, Sinclair JC, Hayward R, Cook DJ Cook RJ, for the evidence-based medicine working group Users' guides to the medical literature. IX. A method for grading health care recommendations. JAMA 1995; 274: $1800-1804$.

25. Kent DL, Haynor DR, Longstreth WT, Larson EB. The clinical efficacy of magnetic resonance imaging in neuroimaging. Ann Intern Med 1994;120:856-871.

26. The Standards of Reporting Trials Group. A proposal for structured reporting of randomized controlled trials. JAMA 1994;272:1926-1931.

27. Ayres JD. The use and abuse of medical practice guidelines. J Leg Med 1994;15:421-443.

28. Garber AM. Can technology assessment control health spending? Health Aff 1994;sum:115-126

29. Eddy DM. Principles for making difficult decisions in difficult times. JAMA 1994;271:1792-1798.

30. Swets JA, Pickett RM, Whitehead SF, et al. Assessment of diagnostic technologies. Science 1979;205:753-759.

31. Aminoff MJ. Criticism in neurology and medicine. Neurology 1994;44:1781-1783.

32. Nuwer MR. On the process for evaluating proposed new diagnostic EEG tests. Brain Topogr 1992;4:243-247.

33. American Electroencephalographic Society. Guidelines for recording clinical EEG on digital media. J Clin Neurophysiol 1994;11:114-115.

34. Gevins A, Le J, Martin NK, Brickett P, Desmond J, Reutter G. High resolution EEG: 124 channel recording, spatial deblurring and MRI integration methods. Electroencephalogr Clin Neurophysiol 1994;90:337-358.

35. Lopes da Silva FH. A critical review of clinical applications of topographic mapping of brain potentials. J Clin Neurophysiol 1990;7:535-551.

36. John ER. The role of quantitative EEG topographic mapping or 'neurometrics' in the diagnosis of psychiatric and neurological disorders: the pros. Electroencephalogr Clin Neurophysiol 1989;73:2-4.

37. Fisch BJ, Pedley TA. The role of quantitative topographic mapping or 'neurometrics' in the diagnosis of psychiatric and neurological disorders: the cons. Electroencephalogr Clin Neurophysiol 1989;73:5-9.

38. Rodin EA. Some problems in the clinical use of topographic EEG analysis. Clin Electroencephalogr 1991;22:23-29. 
39. Welsh JB. Topographic brain mapping: uses and abuses. Hosp Pract (Off Ed) 1992;March 15:163-175.

40. Torello MW. EEG and topographic brain mapping. Handbook of neuropsychology, vol 6. Child neuropsychology. Amsterdam: Elsevier, 1992.

41. Binnie CD, MacGillivray BB. Brain mapping-a useful tool or a dangerous toy? J Neurol Neurosurg Psychiatry 1992;55: $527-529$.

42. Binnie CD, Prior PF. Electroencephalography. J Neurol Neurosurg Psychiatry 1994;57:1308-1319.

43. Kahn EM, Weiner RD, Brenner RP, Coppola R. Topographic maps of brain electrical activity-pitfalls and precautions. Biol Psychiatry 1988;23:628 -636.

44. American Psychiatric Association. Quantitative electroencephalography: a report on the present state of computerized EEG techniques. Am J Psychiatry 1991;148:961-964.

45. Pivik RT, Broughton RJ, Coppola R, Davidson RJ, Fox N, Nuwer MR. Guidelines for the recording and quantitative analysis of electroencephalographic activity in research contexts. Psychophysiology 1993;30:547-558.

46. Duffy FH, Hughes JR, Miranda F, Bernad P, Cook P. Status of quantitative EEG (QEEG) in clinical practice, 1994. Clin Electroencephalogr 1994;25:vi-xxii.

47. Herrmann WM, Kubicki S, Kunkel H, et al. Empfehlungen der deutschen EEG-gesellschaft für das mapping von EEGparametern (EEG-und EP-mapping). Z EEG-EMG 1989;20: $125-132$.

48. Dumermuth G, Ferber G, Herrmann WM, Hinrichs H, Künkel H. International Pharmaco-EEG Group (IPEG). Recommendations for standardization of data acquisition and signal analysis in pharmaco-electroencephalography. Neuropsychobiology 1987;17:213-218.

49. Oken BS, Chiappa KH. Statistical issues concerning computerized analysis of brainwave topography. Ann Neurol 1986; $19: 493-497$.

50. Duffy FH, Bartels PH, Neff R. A response to Oken and Chiappa. Ann Neurol 1986;19:494-497.

51. Duffy FH. Clinical value of topographic mapping and quantified neurophysiology. Arch Neurol 1989;46:1133-1134

52. Duffy FH, Iyer VG, Surwillo WW. Clinical electroencephalography and topographic brain mapping: technology and practice. New York: Springer-Verlag, 1989.

53. Nuwer MR. Quantitative EEG: I. Techniques and problems of frequency analysis and topographic mapping. J Clin Neurophysiol 1988a;5:1-43.

54. Nuwer MR. Quantitative EEG: II. Frequency analysis and topographic mapping in clinical settings. J Clin Neurophysiol $1988 \mathrm{~b} ; 5: 45-85$.

55. Nuwer MN. Uses and abuses of brain mapping. Arch Neurol 1989;46:1134-1136.

56. Iezzoni LI. 'Black box' medical information systems: a technology needing assessment. JAMA 1991;265:3006-3007.

57. Maus A, Endresen J. Misuse of computer-generated results. Med Biol Eng Comput 1979;17:126-129.

58. Nuwer MR, Hauser HH. Erroneous diagnosis using EEG discriminant analysis. Neurology 1994;44:1998-2000.

59. Dolisi C, Suisse G, Delpont E. Quantitative EEG abnormalities and asymmetries in patients with intracranial tumors. Electroencephalogr Clin Neurophysiol 1990;76:13-18.

60. Byring R, Jarvilehto T. Auditory and visual evoked potentials of schoolboys with spelling disabilities. Dev Med Child Neurol 1985;27:141-148.

61. Savage CR, Weilburg JB, Duffy FH, Baer L, Shera DM, Jenike MA. Low level sensory processing in obsessivecompulsive disorder: an evoked potential study. Biol Psychiatry 1994;35:247-252.

62. Vasile RG, Duffy FH, McAnulty G, Mooney JJ, Bloomindale $\mathrm{K}$, Schildkraut JJ. Abnormal visual evoked response in melancholia: a replication study. Biol Psychiatry 1992;31:325-336.

63. Morstyn R, Duffy FH McCarley RW. Altered P300 topography in schizophrenia. Arch Gen Psychiatry 1983;40:729-734.

64. Faux SF, Torello M, McCarley RW, Shenton M, Duffy FH. P300 topography alterations in schizophrenia: a replication study. Electroencephalogr Clin Neurophysiol 1987;40:688-694.

65. Faux SF, Torello M, McCarley RW, Shenton M, Duffy FH. P300 in schizophrenia: confirmation and statistical validation of temporal region deficit in P300 topography. Biol Psychiatry $1987 ; 23: 776-790$
66. Faux SF, Shenton M, McCarley RW, Torello M, Duffy FH P300 in schizophrenia: differentiation of schizophrenics and normal controls is enhanced by Goodin subtraction procedure. Int J Neurosci 1988;39:117 -135.

67. McCarley RW, Shenton ME, O'Donnell BF, et al. Auditory P300 abnormalities and left posterior superior temporal gyrus volume reduction in schizophrenia. Arch Gen Psychiatry 1993;50:190-197.

68. Faux SF, Shenton ME, McCarley RW, Nestor G, Marcy B, Ludwig A. Preservation of P300 event-related potential topographic asymmetries in schizophrenia with use of either linked-ear or nose reference sites. Electroencephalogr Clin Neurophysiol 1990;75:378-391.

69. Lombroso CT, Duffy FH. Brain electrical activity mapping in epilepsies. In: Akimoto H, Kazamatsuri H, Seino M, Ward A, eds. Advances in epileptology: proceedings of XIIIth Epilepsy International Symposium. New York: Raven Press, 1982: 173-179.

70. Lombroso CT, Duffy FH. Brain electrical activity mapping as an adjunct to CT scanning. In: Canger R, Angeleri F, Perry $\mathrm{JK}$, eds. Advances in epileptology: proceedings of XIth Epilepsy International Symposium. New York: Raven Press, 1980:83-88

71. Nuwer MR. Frequency analysis and topographic mapping of EEG and evoked potentials in epilepsy. Electroencephalogr Clin Neurophysiol 1988;69:118-126.

72. Meador KJ, Loring DW, Huh K, et al. Spectral analysis of sphenoidal evoked potentials predicts epileptic focus. Epilepsia 1988;29:434-439

73. Duffy $F$, Jones K, Bartels $P$, McAnulty G, Albert M. Unrestricted principal components analysis of brain electrical activity: issues of data dimensionality, artifact, and utility. Brain Topogr 1992;4:291-307.

74. Duffy FH, Denckla MB, Bartels PH, Sandini G. Dyslexia: egional differences in brain electrical activity by topographic mapping. Ann Neurol 1980;7:412-420.

75. Duffy FH, Denckla MB, Bartels PH, Sandini G, Kiessling LS. Dyslexia: automated diagnosis by computerized classification of brain electrical activity. Ann Neurol 1980;7:421-428.

76. Duffy FH. Topographic display of evoked potentials: clinical applications of brain electrical activity mapping (BEAM) Ann NY Acad Sci 1982;388:183-196.

77. Allison T, Matsumiya Y, Goff GD, Goff WR. The scalp topography of human visual evoked potentials. Electroencephalogr Clin Neurophysiol 1977;42:185-197.

78. Matsumiya Y, Fukuyama Y. Brain topography mapping. In: EEG and EP in pediatrics. Tokyo: Kanehara 1990:351-357.

79. Hughes JR, Kurunlla A, Fino JJ. Topographic analysis of visual evoked potentials from flush and pattern reversal stimuli: evidence for "traveling waves." Brain Topogr 1992;4: $26-28$.

80. Goff GD, Matsumiya Y, Allison T, Goff WR. The scalp topography of human somatosensory and auditory evoked potentials. Electroencephalogr Clin Neurophysiol 1977;42:57-78.

81. John ER, Prichep LS, Easton P. Standardized varimax descriptors of event related potentials: evaluation of psychiatric patients. Psychiatry Res 1994;55:13-40.

82. Whisler JW, ReMine WJ, Leppik IE, McLain LW Jr, Gumnit RJ. Machine detection of spike-wave activity in the EEG and its accuracy compared with visual interpretation. Electroencephalogr Clin Neurophysiol 1982;54:541-551.

83. Quy RJ, Fitch P, Willison RG. High-speed automatic analysis of EEG spike and wave activity using an analogue detection and microcomputer plotting system. Electroencephalogr Clin Neurophysiol 1980;49:187-189.

84. Pauri F, Pierelli F, Chatrian G-E, Erdly WW. Long-term EEG-video-audio monitoring: computer detection of focal EEG seizure patterns. Electroencephalogr Clin Neurophysiol $1992 ; 82: 1-9$

85. Lopes da Silva FH, Van Hulten K, Lommen JG, et al. Automatic detection and localization of epileptic foci. Electroencephalogr Clin Neurophysiol 1977;43:1-13.

86. Liu A, Hahn JS, Heldt GP, Coen RW. Detection of neonatal seizures through computerized EEG analysis. Electroencephalogr Clin Neurophysiol 1992;82:30-37.

87. Ktonas PY. Automated spike and sharp wave (SSW) detection. In: Gevins AS, Rémond A, eds. Methods of analysis of brain electrical and magnetic signals. EEG handbook (re- 
vised series, vol. 1). Amsterdam: Elsevier Science Publishers BV, 1987:211-241.

88. Koffler DJ, Gotman J. Automatic detection of spike-andwave bursts in ambulatory EEG recordings. Electroencephalogr Clin Neurophysiol 1985;61:165-180.

89. Hostetler WE, Doller HJ, Homan RW. Assessment of a computer program to detect epileptiform spikes. Electroencephalogr Clin Neurophysiol 1992;83:1-11.

90. De Oliveira PD, Queiroz C, Lopes da Silva F. Spike detection based on a pattern recognition approach using a microcomputer. Electroencephalogr Clin Neurophysiol 1983;56:97-103.

91. Gotman J. Automatic recognition of epileptic seizures in the EEG. Electroencephalogr Clin Neurophysiol 1982;54:530-540.

92. Gotman J, Ives JR, Gloor P. Automatic recognition of interictal epileptic activity in prolonged FEG recordings. Electroencephalogr Clin Neurophysiol 1979;46:510-520.

93. Gotman J. Automatic seizure detection: improvements and evaluation. Electroencephalogr Clin Neurophysiol 1990;76: 317-324.

94. Gabor AJ, Seyal M. Automated interictal EEG spike detection using artificial neural networks. Electroencephalogr Clin Neurophysiol 1992;83:271-280.

95. Qu H, Gotman J. Improvement in seizure detection performance by automatic adaptation to the EEG of each patient. Electroencephalogr Clin Neurophysiol 1993;86:79-87.

96. $\mathrm{Qu} \mathrm{H}$, Gotman J. A seizure warning system for long-term epilepsy monitoring. Neurology 1995;45:2250-2254.

97. Murro AM, King DW, Smith JR, Gallagher BB, Flanigin HF, Meador K. Computerized seizure detection of complex partial seizures. Electroencephalogr Clin Neurophysiol 1991;79: $330-333$.

98. Jordan KG. Continuous EEG and evoked potential monitoring in the neuroscience intensive care unit. J Clin Neurophysiol $1993 ; 10: 445-475$

99. Jordan KG. Status epilepticus: a perspective from the neuroscience intensive care unit. In: Martin NA, ed. Neurosurgical intensive care. Neurosurg Clin N Am 1994;5:671-686.

100. Nuwer MR. Electroencephalograms and evoked potentials monitoring cerebral function in the neurosurgical intensiv care unit. In: Martin NA, ed. Neurosurgery clinics. Neurosurgical Intensive Care 1994;5:647-659

101. Webber WRS, Litt B, Lesser RP, Fisher RS, Bankman I. Automatic EEG spike detection: what should the computer imitate? Electroencephalogr Clin Neurophysiol 1994;87:364373.

102. Morris GL, Galezowska J, Leroy R, North R. The results of computer-assisted ambulatory 16-channel EEG. Electroencephalogr Clin Neurophysiol 1994;91:229-231.

103. Pietilä T, Vapaakoski S, Nousiainen U, et al. Evaluation of a computerized system for recognition of epileptic activity during long-term EEG recording. Electroencephalogr Clin Neurophysiol 1994;90:438-443.

104. Webber WRS, Litt B, Wilson K, Lesser RP. Practical detection epileptiform discharges (EDs) in the EEG using an artificial neural network: a comparison of raw and parameterized EEG data. Electroencephalogr Clin Neurophysiol 1994; 91:194-204.

105. Lowenstein DH, Aminoff MJ. Clinical and EEG features of status epilepticus in comatose patients. Neurology 1992;42: 100-104.

106. Michelucci R, Tassinari CA, Zapoli R. Status epilepticus. In Gotman J, Ives JR, Gloor P, eds. Long-term monitoring in epilepsy. Amsterdam: Elsevier, 1985:241-265.

107. Bauer G, Aichner F, Mayr U. Nonconvulsive status epilepticus following generalized tonic-clonic seizures. Eur Neurol $1982 ; 21: 411-419$

108. Doose $\mathrm{H}$. Nonconvulsive status epilepticus in childhood: clinical aspects and classification. Adv Neurol 1984;34:115-125.

109. Ellis JM, Lee SI. Acute prolonged confusion in later life as an ictal state. Epilepsia 1978;19:119-128.

110. Escueta AV, Boxley J, Stubbs N, Waddell G, Wilson WA. Prolonged twilight state and automatisms: a case report. Neurology 1974:24:331-339.

111. Tomson T, Svanborg E, Wedlund JE. Nonconvulsive status epilepticus: high incidence of complex partial status. Epilepsia 1986;27:276-285.

112. Chatrian GE, Shaw CM, Leffman H. The significance of periodic lateralized epileptiform discharges in EEG: an electro- graphic, clinical and pathological study. Electroencephalogr Clin Neurophysiol 1964;17:177.

113. Cascino GD. Nonconvulsive status epilepticus in adults and children. Epilepsia 1993;34(suppl 1):S21-S28.

114. Ebersole JS, Wade PB. Spike voltage topography identifies two types of frontotemporal epileptic foci. Neurology 1991;41 1425-1433.

115. Ebersole JS, Wade PB. Spike voltage topography and equivalent dipole localization in complex partial epilepsy. Brain Topogr 1990;3:21-34.

116. Sutherling WW, Crandall PH, Engel J Jr, Darcey TM, Cahan LD, Barth DS. The magnetic field of complex partial seizures agrees with intracranial localizations. Ann Neurol 1987;21: $548-558$.

117. Sutherling WW, Risinger MW, Crandall MD, et al. Focal functional anatomy of dorsolateral frontocentral seizures. Neurology 1990;40:87-98.

118. Sutherling WW, Levesque MF, Crandall PH, Barth DS. A complete physical description of the dynamic electric currents of human partial epilepsy and essential cortex using MEG, EEG, chronic ECoG grid recording, and direct cortical stimulations. In: Lüders H, ed. Epilepsy surgery. New York: Raven Press, 1991:429-450.

119. Sutherling WW, Crandall P, Levesque M, Darcey T, Barth D. Physical interpretation of frontal lobe seizures: the dipole approximation and sensorimotor cortex. In: Chauvel $P$, Delgado-Escueta AV, et al, eds. Adv Neurol 1992;57:339347.

120. Baumgartner C, Lindinger G, Ebner A, et al. Propagation of interictal epileptic activity in temporal lobe epilepsy. Neurology 1995;45:118-122.

121. Ebersole JS. Non-invasive localization of the epileptogenic focus by EEG dipole modeling. Acta Neurol Scand 1994 $152($ suppl ): $20<28$.

122. Alarcon G, Guy CN, Binnie CD, Walker SR, Elwes RDC Polkey CE. Intracerebral propagation of interictal activity in partial epilepsy: implications for source localization. J Neurol Neurosurg Psychiatry 1994;57:435-449.

123. Nakasato N, Levesque MF, Barth DS, Baumgartner C, Rog ers RL, Sutherling WW. Comparisons of MEG, EEG, and ECoG source localization in neocortical partial epilepsy in humans. Electroencephalogr Clin Neurophysiol 1994;91:171178.

124. Wong PKH. Stability of source estimates in rolandic spikes Brain Topogr 1989;2:31-36.

125. Weinberg $\mathrm{H}$, Wong PKH, Crisp D, Johnson B, Cheyne D. Use of multiple dipole analysis for the classification of benign rolandic epilepsy. Brain Topogr 1990;3:183-190.

126. Van der Meij W, Van Huffelen AC, Wieneke GH, Willemse J. Sequential EEG mapping may differentiate "epileptic" from "non-epileptic" rolandic spikes. Electroencephalogr Clin Neurophysiol 1992;82:408-414.

127. Yoshinaga H, Amano $\mathrm{R}$, Oka E, Ohtahara S. Dipole tracing in childhood epilepsy with special reference to rolandic epilepsy. Brain Topogr 1992;4:193-199.

128. Brazier MAB. Interactions of deep structures during seizures in man. In: Petsche H, Brazier MAB, eds. Synchronization of EEG activity in epilepsies. New York: Springer Verlag, 1972b:409-427.

129. Gotman J. Interhemispheric relations during bilateral spikeand-wave activity. Epilepsia 1981;22:453-466

130. Kobayashi K, Ohtsuka $\mathbf{Y}$, Oka E, Ohtahara S. Primary and secondary bilateral synchrony in epilepsy: differentiation by estimation of interhemispheric small time differences during short spike-wave activity. Electroencephalogr Clin Neurophysiol 1992;83:93-103.

131. Hughes JR. Topographic mapping of different types of bilateral spike and wave complexes. J Epilepsy 1990;3:67-74

132. Franaszczuk PJ, Bergey GK, Kaminski MJ. Analysis of mesial temporal seizure onset and propagation using the directed transfer function method. Electroencephalogr Clin Neurophysiol 1994;91:413-427.

133. Lieb JP, Sperling MR, Mendius JR, Skomer CE, Engel J Jr. Visual versus computer evaluation of thiopental-induced EEG changes in temporal lobe epilepsy. Electroencephalogr Clin Neurophysiol 1986;63:395-407.

134. Harner RN, Jackel RA, Mawhinney-Hee MR, Sussman NM 
Computed EEG topography in epilepsy. Rev Neurol (Paris) 1987;143:457-461.

135. Hughes JR, Taber JE, Fino JJ. The effect of spikes and spike-free epochs on topographic brain maps. Clin Electroencephalogr 1991;2215:150-60.

136. Panet-Raymond D, Gotman J. Asymmetry in delta activity in patients with focal epilepsy. Electroencephalogr Clin Neurophysiol 1990;75:474-481.

137. Logar Ch. The EEG mapping in the evaluation of patients with late onset epilepsy. Brain Topogr 1992;4:229-235.

138. Verma NP, Twitty GR, Fuerst DR. Event-related potentials in complex partial seizures. Brain Topogr 1993;6:35-41.

139. Fisher RS, Webber WRS, Lesser RP, Arroyo S, Uematsu S. High-frequency EEG activity at the start of seizures. J Clin Neurophysiol 1992;9:441-448.

140. Alarcon G, Binnie CD, Elwes RDC, Polkey CE. Power spectrum and intracranial EEG patterns at seizure onset in partial epilepsy. Electroencephalogr Clin Neurophysiol 1994;94: $326-337$.

141. Allen PJ, Fish DR, Smith SJ. Very high-frequency rhythmic activity during SEEG suppression in frontal lobe epilepsy. Electroencephalogr Clin Neurophysiol 1992;82:155-159.

142. Johnson SF. Diagnosis by electroencephalographic topography. J Neuroimaging 1993;3:20-27.

143. Oken BS, Chiappa KH, Salinsky M. Computerized EEG frequency analysis: sensitivity and specificity in patients with focal lesions. Neurology 1989;39:1281-1287.

144. Salinsky MC, Oken BS, Kramer RE, Morehead L. A comparison of quantitative EEG frequency analysis and conventional EEG in patients with focal brain lesions. Electroencephalogr Clin Neurophysiol 1992;83:358-366.

145. Brigell MG, Celesia GG, Salvi F, Clark-Bash R. Topographic mapping of electrophysiologic measures in patients with homonymous hemianopia. Neurology 1990;40:1566-1570.

146. Nagata K, Yunoki K, Araki G, Mizukami M. Topographic electroencephalographic study of transient ischemic attacks. Electroencephalogr Clin Neurophysiol 1984;58:291-301.

147. Nagata K, Mizukami M, Araki G, Kawase T, Hirano M Topographic electroencephalographic study of cerebral infarction using computed mapping of the EEG. J Cereb Blood Flow Metab 1982;2:79-88.

148. Nagata K, Tagawa K, Hiroi S, Shishido F, Uemura K. Electroencephalographic correlates of blood flow and oxygen metabolism provided by positron emission tomography in patients with cerebral infarction. Electroencephalogr Clin Neurophysiol 1989;72:16-30.

149. Nagata K. Topographic EEG in brain ischemia: correlation with blood flow and metabolism. Brain Topography 1988;1: 97-106.

150. Nuwer MR, Jordan SE, Ahn SS. Evaluation of stroke using EEG frequency analysis and topographic mapping. Neurology $1987 ; 37: 1153-1159$

151. Jackel RA, Harner RN. Computed EEG topography in acute stroke. Neurophysiol Clin 1989;19:185-197.

152. Faught E. Current role of electroencephalography in cerebral ischemia. Stroke 1993;24:609-613.

153. Ingvar DH, Sjölund B, Ardö A. Correlation between dominant EEG frequency, cerebral oxygen uptake and blood flow. Electroencephalogr Clin Neurophysiol 1976;41:268-276.

154. Jonkman EJ, Poortvliet DCJ, Veering MM, DeWeerd AW, John ER. The use of neurometrics in the study of patients with cerebral ischemia. Electroencephalogr Clin Neurophysiol 1985;61:333-341.

155. Sainio K, Stenberg D, Keskimäki I, Muuronen A, Kaste M Visual and spectral EEG analysis in the evaluation of the outcome in patients with ischemic brain infarction. Electroencephalogr Clin Neurophysiol 1983;56:117-124.

156. Tolonen U, Ahonen A, Sulg IA, et al. Serial measurements of quantitative EEG and cerebral blood flow and circulation time after brain infarction. Acta Neurol Scand 1981;63:145155.

157. Tolonen U, Sulg IA. Comparison of quantitative EEG parameters from four different analysis techniques in evaluation of relationships between EEG and CBF in brain infarction. Electroencephalogr Clin Neurophysiol 1981;51:177-185.

158. Mies G, Hoppe G, Hossmann K-A. Limitations of EEG frequency analysis in the diagnosis of intracerebral diseases. In: Pfurtscheller G, Jonkman EJ, Lopes da Silva FH, eds.
Brain ischemia: quantitative EEG and imaging techniques, vol 62. Amsterdam: Elsevier, 1984:85-103.

159. Chiappa KH, Burke SR, Young RR. Results of electroencephalographic monitoring during 367 carotid endarterectomies: use of a dedicated minicomputer. Stroke 1979;10:381-388.

160. Ahn SS, Jordan SE, Nuwer MR, Marcus DR, Moore WS. Computed electroencephalographictopographic brain mapping. J Vasc Surg 1988;8:247-254.

161. Redekop G, Ferguson G. Correlation of contralateral stenosis and intraoperative electroencephalogram change with risk of stroke during carotid endarterectomy. Neurosurgery 1992; 30:191-194.

162. Kawahara N, Tanaka H, Sakamoto T, et al. Clinical application of the multidimensional neurological monitoring system and the cerebrosystemic hemodynamic profile for critically ill neurosurgical patients. Neurol Med Chir (Tokyo) 1988;28: $27-33$.

163. Labar DR, Fisch BJ, Pedley TA, Fink ME, Solomon RA. Quantitative EEG monitoring for patients with subarachnoid hemorrhage. Electroencephalogr Clin Neurophysiol 1991;78:325-332.

164. Passouant P, Cadihac J, Delange M, Baldy-Moulinier M, Kassabgui ME. Differential electrical stages and cyclic organization of post-traumatic comas: polygraphic recording of long duration. Electroencephalogr Clin Neurophysiol 1965; $18: 720$.

165. Bergamasco B, Bergamini L, Doriguzzi T. Clinical value of the sleep electroencephalographic patterns in post-traumatic coma. Acta Neurol Scand 1968a;44:495-511.

166. Bergamasco B, Bergamini L, Doriguzzi T, et al. EEG sleep patterns as a prognostic criterion in post-traumatic coma. Electroencephalogr Clin Neurophysiol 1986b;24:374-377.

167. Bricolo A, Gentilomo A, Rosadini G, Rossi GF. Long-lasting post-traumatic unconsciousness. Acta Neurol Scand 1968;44: $512-532$.

168. Bricolo A, Turrazzi S, Faccioli F, Odonizzi F, Sciaretta G, Erculiani P. Clinical application of compressed spectral array in long-term EEG monitoring of comatose patients. Electroencephalogr Clin Neurophysiol 1978;45:211-225.

169. Hughes JR, Cayaffa J, Leestma J, Mizuna Y. Alerting "waking" and "sleeping" EEG patterns in a deeply comatose patient. Clin Electroencephalogr 1972;3:86-93.

170. Bricolo A. Electroencephalography in neurotraumatology. Clin Electroencephalogr 1976;7:184-197.

171. Karnaze DS, Marshall LF, Bickford RG. EEG monitoring of clinical coma: spectral array. Neurology 1982;32:289-292

172. Bricolo A, Turrazzi S, Faccioli F. Combined clinical and EEG examinations for assessment of severity of acute head injuries: electrophysiological methods. Acta Neurochir Suppl (Wien) 1979;28:35-39.

173. Steudel WI, Kruger J. Using the spectral analysis of the EEG for prognosis of severe brain injuries in the first posttraumatic week. Acta Neurochir Suppl (Wien) 1979;28:40-42.

174. Cant BR, Shaw NA. Monitoring by compressed spectral array in prolonged coma. Neurology 1984;34:35-39.

175. Prior P. Electroencephalography in cerebral monitoring: coma, cerebral ischemia and epilepsy. In: Stålberg E, Young $\mathrm{RR}$, eds. Clinical neurophysiology, neurology volume I. London: Butterworths, 1981:347-383.

176. Stidham GL, Nugent SK, Rogers MC. Monitoring cerebral electrical function in the ICU. Crit Care Med 1980;8:519-523.

177. Maynard DE, Jenkinson JL. The cerebral function analyzing monitor. Anaesthesia 1984;39:678-690.

178. Archibald JE, Drazkowski JF. Clinical applications of com pressed spectral analysis (CSA) in OR/IC settings: Am J EEG Technol 1985;25:13-36.

179. Dusser A, Navelet Y, Devictor D, Landrieu P. Short- and long-term prognostic value of the electroencephalogram in children with severe head injury. Electroencephalogr Clin Neurophysiol 1989;73:85-93.

180. Rogers AT, Stump DA. Cerebral physiologic monitoring. Neurologic Critical Care 1989;89:845-861.

181. Rivierez M, Landau-Ferey J, Grob R, Grosskopf D, Philippon $\mathrm{J}$. Value of electroencephalogram in prediction and diagnosis of vasospasm after intracranial aneurysm rupture. Acta Neurochir (Wien) 1991;110:17-23.

182. Hilz MJ, Litscher G, Weis M, et al. Continuous multivariable 
monitoring in neurological intensive care patients: preliminary reports on four cases. Intensive Care Med 1991;17:87-93.

183. Chiappa KH. Electrophysiologic monitoring. In: Ropper AH, Kennedy SK, eds. Neurological and neurosurgical intensive care. 2nd ed. Rockville, MD: Aspen Publ., 1987.

184. Brenner RP, Ulrich RF, Spiker DG, et al. Computerized EEG spectral analysis in elderly normal, demented and depressed subjects. Electroencephalogr Clin Neurophysiol 1986;64:483492.

185. Brenner RP, Reynolds CF III, Ulrich RF. Diagnostic efficacy of computerized spectral versus visual EEG analysis in elderly normal, demented and depressed subjects. Electroencephalogr Clin Neurophysiol 1988;69:110-117.

186. Brenner RP, Reynolds CF III, Ulrich RF. EEG findings in depressive pseudodementia and dementia with secondary depression. Electroencephalogr Clin Neurophysiol 1989;72: 298-304.

187. Breslau J, Starr A, Sicotte N, Higa J, Buchsbaum MS. Topographic EEG changes with normal aging and SDAT. Electroencephalogr Clin Neurophysiol 1989;72:281-289

188. Erkinjuntti T, Larsen T, Sulkava R, Ketonen L, Laaksonen $R$, Palo J. EEG in the differential diagnosis between Alzheimer's disease and vascular dementia. Acta Neurol Scand 1988;77:36-43.

189. Schreiter-Gasser U, Gasser T, Ziegler P. Quantitative EEG analysis in early onset Alzheimer's disease: a controlled study. Electroencephalogr Clin Neurophysiol 1993;86:15-22.

190. Schreiter-Gasser U, Gasser T, Ziegler P. Quantitative EEG analysis in early onset Alzheimer's disease: correlations with severity, clinical characteristics, visual EEG and CCT. Electroencephalogr Clin Neurophysiol 1994;90:267-272.

191. Hier DB, Mangone CA, Ganellen R, et al. Quantitative measurement of delta activity in Alzheimer's disease. Clin Electroencephalogr 1991;22:178-182

192. Jordan SE, Nowacki R, Nuwer M. Computerized electroencephalography in the evaluation of early dementia. Brain Topogr 1989;1:271-282

193. Logar $\mathrm{Ch}$, Grabmair W, Schneider G, Lechner H. EEG Veränderungen bei seniler demenz von Alzheimer typ. Z EEG-EMG 1987;18:214-216

194. Prichep LS, John ER, Ferris ER, Reisberg SH, Alper K Cancro R. Quantitative EEG correlates of cognitive deterioration in the elderly. Neurobiol Aging 1994;15:85-90.

195. Mody CK, McIntyre HB, Miller BL, Read SL. Topographic brain mapping and EEG frequency analysis in Alzheimer disease: a preliminary report. Bull Clin Neurosci 1988;53: 94-97.

196. Penttila M, Partanen JV, Soininen H, Riekkinen PJ. Quantitative analysis of occipital EEG in different stages of Alzheimer's disease. Electroencephalogr Clin Neurophysiol 1985 $60: 1-6$

197. Signorino M, Pucci E, Berlardinelli N, Nolfe G, Angeleri F EEG spectral analysis in vascular and Alzheimer dementia. Electroencephalogr Clin Neurophysiol 1995;94:313-325.

198. Soininen H, Partanen J, Laulumma V, Pääkkönen A, Helkala E-L. Serial EEG in Alzheimer's disease: 3 year follow-up and clinical outcome. Electroencephalogr Clin Neurophysiol 1991;79:342-348.

199. Soininen H, Partanen J, Laulumaa V, Helkala E-L, Laakso M, Riekkinen PJ. Longitudinal EEG spectral analysis in early stage of Alzheimer's disease. Electroencephalogr Clin Neurophysiol 1989;72:290-297.

200. Coben LA, Chi D, Snyder AZ, Storandt M. Replication of a study of frequency analysis of the resting awake EEG in mild probable Alzheimer's disease. Electroencephalogr Clin Neurophysiol 1990;75:148-154.

201. Helkala E-L, Laulumaa V, Soininen H, Partanen J, Riekkinen PJ. Different patterns of cognitive decline related to normal or deteriorating EEG in a 3-year follow-up study of patients with Alzheimer's disease. Neurology 1991;41:528-532.

202. Hooijer C, Jonker C, Posthuma J, Visser SL. Reliability, validity and follow-up of the EEG in senile dementia: sequelae of sequential measurement. Electroencephalogr Clin Neurophysiol 1990;76:400-412.

203. Sloan EP, Fenton GW. EEG power spectral and cognitive change in geriatric psychiatry: a longitudinal study. Electroencephalogr Clin Neurophysiol 1993;86:361-367.

204. Sloan EP, Fenton GW, Kennedy NSJ, MacLennan JM. Neu- rophysiology and SPECT cerebral blood flow patterns in dementia. Electroencephalogr Clin Neurophysiol 1994;91:163170

205. Duffy FH, Albert MS, McAnuly G. Brain electrical activity in patients with presenile and senile dementia of the Alzheimer type. Ann Neurol 1984;16:439-448.

206. Holschneider DP, Leuchter AF. Beta activity in aging and dementia. Brain Topogr 1995;8:169-180.

207. Saletu B, Anderer P, Paulus E, et al. EEG brain mapping in diagnostic and therapeutic assessment of dementia. Alzheimer Dis Assoc Disord 1991;5:(suppl 1):S57-S75.

208. Koponen H, Partanen J, Pääkkönen A, Mattila E, Riekkinen PJ. EEG spectral analysis in delirium. J Neurol Neurosurg Psychiatry 1989;52:980-985.

209. Pritchard WS, Duke DW, Coburn KL, et al. EEG-based, neural-net predictive classification of Alzheimer's disease versus control subjects is augmented by non-linear EEG measures. Electroencephalogr Clin Neurophysiol 1994;91: $118-130$.

210. Anderer P, Saleutu B, Klöppel B, Semlitsch HV, Werner H Discrimination between demented patients and normals based on topographic EEG slow wave activity: comparison between $z$ statistics, discriminant analysis and artificial neural network classifiers. Electroencephalogr Clin Neurophysiol 1994;91:108-117.

211. Szelies B, Mielke R, Herholz K, Heiss WD. Quantitative topographical EEG compared to FDG PET for classification of vascular and degenerative dementia. Electroencephalogr Clin Neurophysiol 1994;91:131-139.

212. Besthorn C Förstl H, Geiger-Kabisch C, Sattel H, Gasser T, Schreiter-Gasser U. EEG coherence in Alzheimer disease Electroencephalogr Clin Neurophysiol 1994;90:242-245.

213. Leuchter AF, Newton TF, Cook JA, Walter DO, Rosenberg Thompson S, Lachenbruch PA. Changes in brain functiona connectivity in Alzheimer-type and multi-infarct dementia. Brain 1992;115:1543-1561.

214. Goodin DS, Squires KC, Starr A. Long latency event-related components of the auditory evoked potential in dementia. Brain 1978;101:635-648.

215. Goodin DS. Event-related (endogenous) potentials. In: Electrodiagnosis in clinical neurology. 3rd ed. New York Churchill Livingstone, 1992:627-648.

216. Polich J, Ladish C, Bloom FE. P300 assessment of early Alzheimer's disease. Electroencephalogr Clin Neurophysiol 1990;77:179-189.

217. Marsh JT, Schubarth G, Brown WS, et al. PET and P300 relationships in early Alzheimer's disease. Neurobiol Aging 1990;11:471-476.

218. Maurer K, Ihi R, Dierks Th. Topographie der P300 in der psychiatrie: II. Kognitive P300-felder bie demenz. Z EEGEMG 1988;19:26-29.

219. Holt LE, Raine A, Pa G, Schneider LS, Henderson VW, Pollock VE. P300 topography in Alzheimer's disease. Psychophysiology 1995;32:257-265.

220. Hamburger HL, Triantafyllou NI. Clinical applications of auditory event related potentials in neurology. Brain Topogr $1990 ; 3: 49-52$

221. Sagalés T, Gimeno V, de la Calzada MD, Casellas F, Macià MD, Soriano MV. Brain mapping analysis in patients with hepatic encephalopathy. Brain Topogr 1990;2:221-228.

222. Van der Rijt C, Schalm SW. Quantitative EEG analysis and survival in liver disease. Electroencephalogr Clin Neurophysiol 1985;61:502-504.

223 Van der Rijt CD, Schalm SW, De Groot GH, De Vlieger M. Objective measurement of hepatic encephalopathy by means of automated EEG analysis. Electroencephalogr Clin Neurophysiol 1984;57:423-426.

224. Epstein CM, Riether AM, Henderson RM, Cotsonis GA. EEG in liver transplantation: visual and computerized analysis. Electroencephalogr Clin Neurophysiol 1992;83:367-371.

225. Hughes JR, Wilson WP. EEG and evoked potentials in psychiatry and behavioral neurology. Boston, MA: Butterworth Publishers, 1993.

226. American Psychiatric Association. Quantitative electroencephalography: a report on the present state of computerized EEG techniques. American Psychiatric Association Task Force on Quantitative Electrophysiological Assessment. Am J Psychiatry 1991;148:961-964. 
227. Hooshmand H, Beckner E, Radfar F. Technical and clinical aspects of topographic brain mapping. Clin Electroencephalogr 1989;20:235-247.

228. Johnstone $J$, Thatcher RW. Quantitative EEG analysis and rehabilitation issues in mild traumatic brain injury. Journal of Insurance Medicine 1991;23:228-232.

229. Green J, Leon-Barth C, Dieter J, Benfante P, Walker D. Somatosensory evoked responses via electronic brain imaging (EBI). Clin Electroencephalogr 1992;23:79-88.

230. Jerrett SA, Corsak J. Clinical utility of topographic EEG brain mapping. Clin Electroencephalogr 1988;19:134-143.

231. Wirsén A, Stenberg G, Rosén I, Ingvar DH. Quantified EEG and cortical evoked responses in patients with chronic traumatic frontal lesions. Electroencephalogr Clin Neurophysiol 1992;84:127-138.

232. Tebano MT, Cameroni M, Gallozzi G, et al. EEG spectral analysis after minor head injury in man. Electroencephalogr Clin Neurophysiol 1988;70:185-189.

233. Thatcher RW, Walker RA, Gerson I, Geisler FH. EEG discriminant analyses of mild head trauma. Electroencephalogx Clin Neurophysiol 1989;73:94-106.

234. Thatcher RW, Cantor DS, McAlaster R, Geisler F, Krause P. Comprehensive predictions of outcome in closed head-injured patients. The development of prognostic equations. Ann NY Acad Sci 1991;620:82-101.

235. Dusser A, Navelet Y, Devictor D, Landrieu P. Short- and long-term prognostic value of the electroencephalogram in children with severe head injury. Electroencephalogr Clin Neurophysiol 1989;73:85-93.

236. Moulton RJ, Marmarou A, Ronen J, et al. Spectral analysis of the EEG in craniocerebral trauma. Can J Neurol Sci 1988; 15:82-86.

237. Hutchinson DO, Frith RW, Shaw NA, Judson JA, Cant BR. A comparison between electroencephalography and somatosensory evoked potentials for outcome prediction following severe head injury. Electroencephalogr Clin Neurophysiol 1991;78:228-233

238. Stone JL, Ghaly RF, Hughes JR. Electroencephalography in acute head injury. Electroencephalogr Clin Neurophysio 1988;5:125-133.

239. Rae-Grant AD, Barbour PJ, Reed J. Development of a novel EEG rating scale for head injury using dichotomous variables. Electroencephalogr Clin Neurophysiol 1991;79:349-357.

240. Synek V. Prognostically important EEG coma patterns in diffuse anoxic and traumatic encephalopathies in adults. $\mathrm{J}$ Clin Neurophysiol 1988;5:161-174.

241. Rumpl E, Lorenzi E, Hackl J, Gerstenbrand F, Hengl W. The EEG at different stages of acute secondary traumatic midbrain and bulbar brain syndromes. Electroencephalogr Clin Neurophysiol 1981;46:487-497.

242. Colon EJ, Notermans SLH, de Weerd JPC, Kap J. The discriminating role of EEG power spectra in dyslexic children. J Neurol 1979;221:257--262.

243. Sutton JP, Whitton JL, Topa M, Moldofsky H. Evoked potential maps in learning disabled children. Electroencephalogr Clin Neurophysiol 1986;65:399-404.

244. Galin D, Raz J, Fein G, Johnstone J, Herron J, Yingling C EEG spectra in dyslexic and normal readers during oral and silent reading. Electroencephalogr Clin Neurophysiol 1992; 82:87-101.

245. Hughes JR, Park GE. The EEG in dyslexia. In: Kellaway P, Petersen I, eds. Clinical EEG of children. Stockholm: Almquist \& Wiksell, 1958:307-327.

246. Ahn H, Prichep L, John ER, Baird H, Trepetin M, Kaye H. Developmental equations reflect brain dysfunctions. Science 1980;210:1259-1262

247. Johnstone J, Galin D, Fein G, Yingling C, Herron J, Marcus $\mathrm{M}$. Regional brain activity in dyslexie and control children during reading tasks: visual probe event-related potentials. Brain Lang 1984:21:233-254.

248. Fein G, Galin D, Johnstone J, Yingling C, Marcus M, Kiersch M. EEG power spectra in normal and dyslexic children. I. Reliability during passive conditions. Electroencephalogr Clin Neurophysiol 1983;55:399-405.

249. Fein G, Galin D, Yingling CD, Johnstone J, Davenport L Herron J. EEG spectra in dyslexic and controls boys during resting conditions. Electroencephalogr Clin Neurophysiol 1986;63:87-97.
250. Rumsey JM, Coppola R, Denckla MB, Hamburger SD, Kruesi MJ. EEG spectra in severely dyslexic men: rest and word and design recognition. Electroencephalogr Clin Neurophysiol 1989;73:30-40

251. Byring RF. EEG correlation topography in poor spellers. Electroencephalogr Clin Neurophysiol 1986;63:1-9.

252. Duffy FH, Denckla MB, Bartels PH, Sandini G. Dyslexia: regional differences in brain electrical activity by topographic mapping. Ann Neurol 1980a; 7:412-420.

253. Duffy FH, Denckla MB, Bartels PH, Sandini G, Kiessling LS Dyslexia: Automated diagnosis by computerized classification of brain electrical activity. Ann Neurol 1980b;7:421-428.

254. Byring RF, Salmi TK, Sainio KO, Örn HP. EEG in children with spelling disabilities. Electroencephalogr Clin Neurophysiol 1991;79:247-255.

255. Flynn JM, Deering WM. Subtypes of dyslexia: investigation of Boder's system using quantitative neurophysiology. Dev Med Child Neurol 1989;31:215-223.

256. Harmony T, Alvarez A, Pascual R, et al. EEG maturation of children with different economic and psychosocial characteristics. Int $J$ Neurosei 1987;31:103-113.

257. Harmony T, Marosi E, Becker J, Rodríguez M, Reyes A Fernández T, Silva J, Bernal J. Longitudinal quantitative EEG study of children with different performances on a reading-writing test. Electroencephalogr Clin Neurophysiol 1995;95:426-433

258. Chabot RJ, Merkin H, Wood LM, Davenport TL, Serfontein G. Sensitivity and specificity of QEEG in children with attention deficit or specific developmental learning disorders. Clin Electroencephalogr 1996;27:26-34.

259. Levy F, Ward PB. Neurometrics, dynamic brain imaging and attention deficit hyperactivity disorder. J Paediatr Child Health 1995;31:279-283.

260. Thatcher RW, Lester ML. Nutrition, environmental toxins and computerized EEG: a mini-max approach to learning disabilities. J Learning Disab 1985;18:287-297.

261. Mann CA, Lubar JF, Zimmerman AW, Miller CA, Muenchen RA. Quantitative analysis of EEG in boys with attentiondeficit-hyperactivity disorder: controlled study with clinical implications. Pediatr Neurol 1992;8:30-36.

262. Suffin SC, Emory WH. Neurometric subgroups in attentional and affective disorders and their association with pharmacotherapeutic outcome. Clin Electroencephalogr 1995;26:1-8.

263. Yingling CD, Galin D, Fein G, Peltzman D, Davenport L Neurometrics does not detect 'pure' dyslexics. Electroencephalogr Clin Neurophysiol 1986;63:426-430.

264. Drake ME, Du Bois C, Huber S, Pakalnis A, Denio LS. EEG spectral analysis and time domain descriptors in headache Headache 1988;28:201-203.

265. Drake ME, Hietter SA, Padamadan H, Bogner JE. Computerized EEG frequency analysis in Gilles de la Tourette syndrome. Clin Electroencephalogr 1991;22:250 - 253 .

266. Hughes JR, Robbins LD. Brain mapping in migraine. Clin Electroencephalogr 1990;21:14-24.

267. Jonkman EJ, Lelieveld MHJ. EEG computer analysis in patients with migraine. Electroencephalogr Clin Neurophysiol 1981;52:652-655

268. Jonkman EJ, DeWeerd AW, Poortvliet DCJ, Veldhuizen RJ Emmen H. Electroencephalographic studies in workers exposed to solvents or pesticides. Electroencephalogr Clin Neurophysiol 1992;82:438-444.

269. Juhász Cs, Szirmai I. Spectral EEG parameters in patients with tick-bone encephalitis: a follow-up study. Clin Electroencephalogr 1993;24:53-58.

270. John ER, Prichep LS, Friedman J, Easton P. Neurometrics: computer-assisted differential diagnosis of brain dysfunctions. Science 1988;293:162-169.

271. Mas F, Prichep LS, Cancro R, John ER, Alper K Neurometric-quantitative EEG as a diagnostic adjunct in clinical psychiatry. Eur Psychiatry 1991;6:131-139.

272. Prichep LS, John ER. QEEG profiles of psychiatric disorders. Brain Topogr 1992;4:249-257.

273. Prichep LS, Mas F, Hollander E, et al. Quantitative electroencephalographic subtyping of obsessive-compulsive disorder. Psychiatry Res 1993;50:25-32.

274. Shagass C, Roemer RA. Evoked potential topography in major depression. II. Comparisons between subgroups. Int J Psychophysiol 1992;13:255-261. 
275. John ER, Ahn H, Prichep L, Trepetin M, Brown D, Kaye H. Developmental equations for the electroencephalogram. Science 1980;210:1225-1258

276. Itil TM. Qualitative and quantitative EEG findings in schizophrenia. Schizophr Bull 1977;3:61-79.

277. Morstyn R, Duffy FH, McCarley W. Altered topography of EEG spectral content in schizophrenia. Electroencephalogr Clin Neurophysiol 1983a;56:263-271.

278. Morstyn R, Duffy FH, McCarley W. Altered P300 topography in schizophrenia. Arch Gen Psychiatry 1983b;40:729 -734.

279. Faux SF, McCarley RW, Nestor PG, et al. P300 topographic asymmetries are present in unmedicated schizophrenics. Electroencephalogr Clin Neurophysiol 1993;88:32-41.

280. Harmony T, Fernández-Bouzas A, Marosi E, et al. Correlation between computed tomography and voltage and current source density spectral EEG parameters in patients with brain lesions. Electroencephalogr Clin Neurophysiol 1993;87: 196-205.

281. Chen ACN. Human brain measures of clinical pain: a review. I. Topographic mappings. Pain 1993;54:115-132.

282. Garber HJ, Weilburg JB, Duffy FH, Manschreck TC. Clinical use of topographic brain electrical activity mapping in psychiatry. J Clin Psychiatry 1989;50:205-211

283. Abraham HD, Duffy FH. Computed EEG abnormalities in panic disorder with and without premorbid drug abuse. Biol Psychiatry 1991;29:687-690.

284. Ford MR, Goethe JW, Dekker DK. EEG coherence and power in the discrimination of psychiatric disorders and medication effects. Biol Psychiatry 1986;21:1175-1188.

285. Prichep LS, Lieber AL, John ER, et al. Quantitative EEG in depressive disorders. In: Shagass C, Josiassen RC, Roemer $\mathrm{RA}$, eds. Brain electrical potentials and psychopathology. Amsterdam: Elsevier, 1986:223-224.

286. Merrin EL, Floyd TC, Fein G. EEG coherence in unmedicated schizophrenic patients. Biol Psychiatry 1989;25:60-66.

287. John ER, Prichep LS, Alper KR, et al. Quantitative electrophysiological characteristics and subtyping of schizophrenia. Biol Psychiatry 1994;36:801-826.

288. Pollock VE, Schneider LS. Quantitative, waking EEG r search on depression. Biol Psychiatry 1990;27:757-780.

289. Shenton ME, Faux SF, McCarley RW, et al. Correlations between abnormal auditory P300 topography and positive symptoms in schizophrenia: a preliminary report. Biol Psy chiatry 1989;25:710-716

290. Struve FA, Straumanis JJ, Patrick G. Persistent topographic quantitative EEG sequelae of chronic marijuana use: a replication study and initial discriminant function analysis. Clin Electroencephalogr 1994;25:63-75

291. Struve FA, Straumanis JJ, Patrick G, Price L. Topographic mapping of quantitative EEG variables in chronic heavy marijuana users: empirical findings with psychiatric patients. Clin Electroencephalogr 1989;20:6-23.

292. Alper KR, Chabot RJ, Kim AH, Prichep LS, John ER. Quantitative EEG correlates of crack cocaine dependence. Psychiatry Res $1990 ; 35: 95-106$

293. Roemer RA, Cornwell A. Jackson P, Dewart D. Quantitative EEG measures: correlations with lifetime exposure to cocaine, alcohol, marijuana in chronic polydrug abusers. Biol Psychiatry 1994;35:624-625.

294. Cornwell A, Roemer RA, Jackson P, Dew D. Paroxysmal-like EEG abnormalities associated with chronic polydrug abuse. Biol Psychiatry 1994;35:692-693.

295. Herning RI, Glober BJ, Koeppl B, Phillips RL, London ED Cocaine induced increases in EEG alpha and beta activity: evidence for reduced cortical processing. Neuropsychopharmacology 1994;11:1-9.

296. Herning RI, Jones TR, Hooker WD, Mendelson J, Blackwell L. Cocaine increases EEG beta: a replication and extension of Hans Berger's historic experiments. Electroencephalogr Clin Neurophysiol 1985;60:470-477.

297. Lukas SE, Mendelson JH, Woods BT, Mello NK, K-Teoh S. Topographic distribution of EEG alpha activity during ethanol-induced intoxication in women. J Stud Alcohol 1989; 50:176-184

298. Prichep LS, Mas F, Hollander E, et al. Quantitative electroencephalographic (QEEG) subtyping of obsessive compulsive disorder. Psychiatry Res 1993;50:25-32.

299. Czobor P, Volavka J. Pretreatment EEG predicts short-term

292 NEUROLOGY 49 July 1997 response to haloperidol treatment. Biol Psychiatry 1991;30: 927-942.

300. Czobor P, Volavka J. Quantitative EEG electroencephalogram of effect of risperidone in schizophrenic patients. J Clin Psychopharmacol 1993;13:332-342.

301. John ER, Easton P, Prichep LS, Friedman D. Standardized varimax descriptors of ERPs. II. Evaluation of psychiatric patients. Psychiatry Res 1994;55:13-40.

302. Hughes JR, Kuhlman DT, Fichtner CG, Gruenfeld MJ. Brain mapping in a case of multiple personality. Clin Electroencephalogr 1990;21:200-209.

303. Prichep LS, Kowalik SC, Alper K, de Jesus C. Quantitative EEG characteristics of children exposed in utero to cocaine. Clin Electroencephalogr 1995;26:166-172.

304. Reeves RR, Struve FA, Patrick G, Bullen J. Topographic quantitative EEG measures of alpha and theta power changes during caffeine withdrawal; preliminary findings from normal subjects. Clin Electroencephalogr 1995;26:154162.

305. Chabot R, Segal L. QEEG and evoked potentials in central nervous system Lyme disease. Clin Electroencephalogr 1995; $26: 137-145$

306. Fernandez-Bouzas A, Harmony T, Galán L, et al. Comparison of $\mathrm{Z}$ and multivariate statistical brain electromagnetic maps for the localization of brain lesions. Electroencephalogr Clin Neurophysiol 1995;95:372-380.

307. Harmony T, Fernandez-Bouzas A, Marosi E, et al. Frequency source analysis in patients with brain lesions. Brain Topogr 1995;8:109-117.

308. Zhavoronkova LA, Kholodova NB, Zubovsky GA, Gogitidze NV Koptelov YM EEG power mapping, dipole source and coherence analysis in Chernobyl patients. Brain Topogr $1995 ; 8: 161-168$

Johnstone J, Giannini AJ. Applications of quantitative EEG/EP in psychiatry. Psychiatric Ann 1990;20:405-411.

310. Hoffman DA. Finally, accurate diagnosis and quantification of mild closed head injury (with implications for treatment) Trial Talk, June, 1992:152-153.

311. Epstein CM. Computerized EEG in the courtroom. Neurology 1994;44:1566-1569.

312. Mervis J. Supreme court to judges: start thinking like scientists. Science 1993;261:22.

313. Gold JA, Zaremski MJ, Rappaport Lev E, Shefrin DH. Daubert $\mathrm{v}$ Merrell Dow. The supreme court tackles scientific evidence in the courtroom. JAMA 1993;270:2964-2967.

314. Ayala FJ, Black B. Science and the courts. Am Scientist 1993;81:230-239.

315. Annas GJ. Scientific evidence in the courtroom. The death of the Frye rule. N Engl J Med 1994;330:1018-1021.

316. Frye v. U.S., 1293 F. 1013,1014 (1923). See Sterling v. Velsicol Chemical Corp., 855 F.2d 1188 (6th Cir. 1988).

317. State of Arizona v. Zimmerman, 802 P.2d 1024 (Ariz.App 1990).

318. Head v. Lithonia Corp., Inc., 881 F.2d 941 (10th Cir. 1989).

319. Brownell et al. v. Bulldog Trucking Co., Civ. 4-91-0005, U.S District Court, Eastern Dist. of Tennessee, Memorandum Opinion, 1993.

320. Daubert v. Merrell Dow Pharmaceuticals, No. 92-102, 1993 U.S. LEXIS 4408 (June 28, 1993).

321. American Electroencephalographic Society. Minimum technical requirements for performing clinical electroencephalography. J Clin Neurophysiol 1994;11:2-5.

322. American Electroencephalographic Society. Minimum technical standards for pediatric electroencephalography. J Clin Neurophysiol 1994;11:6-9.

323. American Electroencephalographic Society. Standards for practice in clinical electroencephalography. $J$ Clin Neurophysiol 1994;11:14-15.

324. International Federation of Societies for Electroencephalography and Clinical Neurophysiology. Recommendations for the practice of clinical neurophysiology. Amsterdam: Elsevier, 1983.

325. Nuwer MR, Lehmann D, Lopes da Silva F, Matsouka S, Sutherling W, Vibert JF. IFCN guidelines for topographic and frequency analysis of EEGs and EPs. Report of an IFCN committee. Electroencephalogr Clin Neurophysiol 1994;91: $1-5$. 


\section{Neurology}

Assessment of digital EEG, quantitative EEG, and EEG brain mapping: Report of the American Academy of Neurology and the American Clinical Neurophysiology Society* [RETIRED]

Marc Nuwer

Neurology 1997;49;277-292

DOI 10.1212/WNL.49.1.277

This information is current as of July 1,1997

Updated Information \& Services

Citations

Permissions \& Licensing

Reprints including high resolution figures, can be found at: http://n.neurology.org/content/49/1/277.full

This article has been cited by 7 HighWire-hosted articles: http://n.neurology.org/content/49/1/277.full\#\#otherarticles

Information about reproducing this article in parts (figures,tables) or in its entirety can be found online at:

http://www.neurology.org/about/about_the_journal\#permissions

Information about ordering reprints can be found online:

http://n.neurology.org/subscribers/advertise

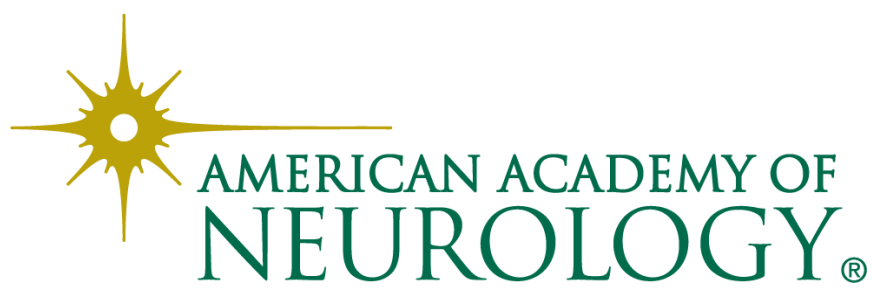

